\title{
Crímenes Y Montaje Como Política INDÍGENA: El CASO HURACÁN, El COMANDO JUNGLA Y LOS EFECTOS EN NIÑOS, NIÑAS Y ADOLESCENTES MAPUCHE
}

\section{Centro de Investigaciones y Defensa Sur (Cidsur) ${ }^{1}$}

\section{Resumen}

El presente artículo trata sobre la política de criminalización implementada en contra de las comunidades mapuche que se han movilizado estas últimas décadas por reivindicaciones políticas y territoriales. Se sustenta sobre diversos casos de estudio, además de la misma experiencia de los autores en materia de defensa penal y de litigación estratégica en contexto de reivindicación mapuche. Un primer apartado explica cómo la criminalización se ha vuelto una verdadera política pública, antes de analizar dos casos claves: el caso Huracán y el asesinato de Camilo Catrillanca, que muestran cómo las mismas comunidades, con el apoyo de abogados públicos e independientes, han usado el derecho en contra del mismo Estado chileno. Por último, se presentan los efectos de esta criminalización, en particular, sobre las niñas, niños, adolescentes y jóvenes de comunidades mapuche en resistencia. Los distintos casos analizados dan cuenta de una política sistémica y generalizada de criminalización hacia el movimiento mapuche, lo que permite concluir que crímenes y montajes forman parte de las políticas actuales del Estado chileno para

1 Este capítulo es el producto de un trabajo colectivo realizado en el seno del Centro de Investigaciones y Defensa Sur (Cidsur) que reúne abogados, abogadas, profesionales, académicos y académicas de distintas especialidades. Cuenta con las contribuciones de las abogadas Pamela Nahuelcheo, Karina Riquelme, la psicóloga Claudia Molina, de los abogados Sebastián Saavedra y Eduardo Painevilo, y del antropólogo Fabien Le Bonniec, este último siendo también académico del Núcleo de Investigación en Estudios Interétnicos e Interculturales de la Universidad Católica de Temuco. 
responder no solo a legítimas reivindicaciones en torno a derechos indígenas reconocidos internacionalmente, sino que también, a demandas relacionadas por una democratización del país y su sistema judicial.

Palabras claves: Mapuche, Criminalización de la protesta, Represión judicial, Política indígena, Judicialización, Movimientos, Indígenas.

\section{Introducción}

Estas dos últimas décadas en Chile han estado marcadas por diversos acontecimientos relacionados con lo que muchos han denominado ligeramente "conflicto mapuche" o "conflicto chileno-mapuche". Hechos que han provocado preocupación en organismos de derechos humanos tanto a nivel nacional como internacional ${ }^{2}$. El nuevo ciclo de movilizaciones mapuche iniciado por los "acontecimientos de Lumaco"3, en pleno conflicto Ralco, ha llevado consigo el aumento de

2 Corte IDH. Caso Norín Catrimán y otros Vs. Chile. Fondo, Reparaciones y Costas. Sentencia de 29 de mayo de 2014. Serie C No. 279 , párr. 218-225; CIDH; ONU, Comité para la eliminación de la Discriminación Racial, Observaciones finales sobre los informes periódicos 19 a 21 de Chile, 23 de septiembre 2013, CERD/C/CHL/CO/19-21, párr. 14; ONU, Declaración del Relator Especial sobre la promoción y la protección de los derechos humanos y libertades fundamentales en la lucha contra el terrorismo de fecha 30 de julio de 2013, sobre su visita a Chile del 17 al 30 de julio de 2013, disponible en: https:// newsarchive.ohchr.org/SP/NewsEvents/Pages/DisplayNews.aspx?NewsI $\mathrm{D}=13598 \&$ LangID=S; ONU, Informe del Relator Especial sobre la promoción y protección de los derechos humanos y las libertades fundamentales en la lucha contra el terrorismo, Ben Emmerson, sobre su Misión a Chile, 14 de abril de 2014, A/HRC/25/59/Add.2, párr. 54; ONU, Observaciones finales del Comité de Derechos Humanos, Chile, 17 de abril de 2007, CCPR/C/CHL/C0/5, párr. 7.

3 En noviembre de 1997, se produce el incendio de tres camiones madereros de pino insigne en la Comuna de Lumaco. Según Pairicán, "existe un consenso, entre la militancia mapuche y los investigadores del tema, de que los sucesos de Lumaco marcaron un punto de inflexión en el desarrollo de la historia mapuche. Algunos han planteado que es el 'detonante organizativo' de la Coordinadora de Comunidad en Conflicto Arauco-Malleco (CAM); otros han señalado que desde ese momento emergió el 'conflicto mapuche'; y una tercera óptica ha planteado que es el surgimiento de un movimiento de resistencia mapuche" (2014: 93). 
la represión, principalmente por parte de agentes estatales, bajo la forma de innumerables allanamientos, detenciones, enjuiciamientos de comuneros, líderes y activistas mapuche, pero también una multitud de personas heridas e incluso, varias asesinadas.

Es al comienzo de los años 2000, cuando se inicia la Reforma Procesal Penal en La Araucanía, que se empieza a hablar de "criminalización de las demandas mapuche" (Couso, 2013; Mella, 2007; Correa y Mella, 2010; Mella, 2014) o de "presos políticos mapuche" (Le Bonniec, 2014), mientras que en las cárceles del sur del país aparecen los "módulos de comuneros mapuche" (González, 2017). Hoy en día se estima en aproximadamente 30 el número de activistas o dirigentes mapuche recluidos en distintos centros penitenciarios del sur del país, dentro de los cuales hay autoridades tradicionales, tales como el machi Celestino Córdoba o los lonko Facundo Jones Huala y Alberto Curamil, este último siendo condecorado con el premio ambiental Goldman en abril de 2019. Es durante este mismo periodo que aparecieron los primeros "jóvenes mártires mapuche" muertos en manos de la policía chilena, crímenes que no recibieron las penas acordes a la gravedad del delito o que por mucho tiempo se mantuvieron en la impunidad, gracias a la vigencia de la Justicia Militar. Todos estos acontecimientos, punteados por éxitos y reveces en los tribunales para los mapuche, han alimentado una perversa rutina, donde se han naturalizado los discursos que justifican la represión, entendida como las acciones y medidas que vulneran directamente los derechos individuales y colectivos de las comunidades que se movilizan, y de todo aquel que las apoye.

Sin duda, lo acontecido a nivel judicial durante el año 2018, ha constituido un notable giro en tal proceso. El montaje policial develado en el caso Huracán, la reapertura del caso Lemun, recomendada por la Comisión Interamericana de Derechos Humanos, y la formalización de ocho funcionarios de Carabineros a raíz del asesinato de Camilo Catrillanca, pueden ser considerados como un avance en la lucha contra la impunidad de la violencia estatal aplicada a la población mapuche, lo que ha reformulado la calidad procesal de los mismos en los tribunales no solo como imputados, sino también como víctimas de montajes, asesinatos y torturas. Como consecuencia, en la actualidad, la litigación de "casos mapuche" no se reduce solo a defender, sino también a interponer querellas en el anhelo de obtener 
justicia para una colectividad que históricamente ha sido discriminada y sus derechos vulnerados dentro de los mismos Tribunales de Justicia. De t,al forma, la labor de los abogados y abogadas, y profesionales en este ámbito, ha adquirido a lo largo de los años el estatus del litigio estratégico en derechos humanos, que no solo se ha sustentado sobre el uso del "arma del derecho", sino que también ha debido integrar diversas herramientas de la psicología, el trabajo social e incluso de la antropología, con el fin de evidenciar las vulneraciones de la integridad sociocultural tanto de los individuos como de los colectivos.

Después de explicar cómo la criminalización se ha vuelto una verdadera política pública, se analizarán dos casos claves en los cuales ha actuado como interviniente el equipo del Centro de Investigación y Defensa Sur (Cidsur), desde el año 2018 hasta la actualidad, y que ilustran cómo el uso del derecho estatal se ha vuelto un registro de acción para las personas mapuche que ven sus derechos vulnerados. En un último apartado, se abordarán los distintos efectos de esta criminalización, en particular sobre las niñas, niños, adolescentes y jóvenes de comunidades mapuche en resistencia.

\section{La criminalización como política pública}

La judicialización o criminalización de los movimientos sociales se presenta como un fenómeno global, con matices y formas locales, pero cuyo denominador común es la acción del Estado y de sus instituciones a través del uso del derecho penal y de las fuerzas policiales en contra de determinados grupos contestatarios, con el objetivo de poner fin a sus actos de protesta. Constituye un elemento de las políticas públicas y de las respuestas de los gobiernos a las manifestaciones de diversa índole, presentes en todos los países democráticos en tiempos de crisis. Forma parte de los procesos políticos constituidos de interacciones polimorfas entre Estado y movimientos sociales que, en determinadas contiendas, pueden tomar un carácter más violento y así conducir a la radicalización, la violencia colectiva y abrir nuevos ciclos reivindicatorios. Por esto, es importante destacar los aspectos procesales e interaccionales entre actores estatales y miembros de los movimientos sociales e indígenas, en la construcción de la acción protestataria y de su represión (Rojas Pedemonte y Miranda, 2017). Esta acción represiva por parte del 
Estado y sus agentes se presenta como legítima, respondiendo a comportamientos, acciones y discursos considerados como ilegales y, por tanto, sujetos a amonestación y sanción. La represión hacia los movimientos sociales puede también tomar formas más sutiles y, sobre todo, menos visibles, con el fin de invisibilizar (a diferencia de los juicios públicos) y despolitizar la acción estatal. Este tipo de represión, conocido como soft-repression (Marx Ferree, 2005), puede tomar la forma de seguimientos, controles reiterados de identidad, allanamientos, detenciones arbitrarias, intervenciones de teléfono o de correo electrónico, censura o estigmatización. Es decir, un conjunto de situaciones más cotidianas difícilmente denunciables. El fin que siguen estas acciones es el mismo que la represión "clásica", vale decir, desmovilizar y contrarrestar todo tipo de acción contestataria, pero de forma más discreta.

En el contexto chileno, el proceso de criminalización de las demandas mapuche se relaciona con uno de los riesgos identificado por el antropólogo Guillaume Boccara al explicar que "ubicarse fuera de los lugares de diálogo interculturales definidos por el Estado implica marginarse, deslegitimarse e, incluso, colocarse al margen de la legalidad" (2012: 20). Las denominadas "políticas interculturales" promovidas a partir de la promulgación de la Ley Indígena (Ley 19.253), sin duda, han constituido importantes avances en el reconocimiento de los pueblos indígenas y de su cultura, particularmente en el ámbito de la educación o de la salud. Pero tuvieron otros efectos al instalarse en una contienda multicultural neoliberal marcada por la emergencia de voces críticas hacia este sistema, y denunciando las desigualdades, injusticias y asimetrías producidos por éste, como también las formas variadas de expoliación y extractivismo que afectan a sus territorios históricos (Colectivo Editorial Mapuexpress, 2016).

El multiculturalismo se ha impuesto como una forma de gobernanza y administración de la diversidad que se ha sustentado en Chile sobre la retórica de la interculturalidad. Las políticas públicas que han derivado de una perspectiva funcional y despolitizada de la interculturalidad se han constituido en verdaderos dispositivos interculturales de control y de división del mundo social indígena, teniendo, entre otros efectos, la criminalización de los "rebeldes" o "terroristas". Efectivamente, al ofrecer como único espacio de mediación e interculturalidad, aquellos 
espacios institucionales que excluyen la posibilidad de abordar asuntos políticos o territoriales, estas políticas crean dos categorías ficticias de población, pero muy activas en los discursos públicos y las representaciones sociales, constituidas por un lado por el "indígena permitido" o "indígena-proyecto" y, por otro lado, por el "terrorista" (Hale y Millaman, 2006). A cada una de estas categorías, y según la misma lógica, se les atribuye un territorio a "etno-desarrollar" o a "pacificar", inscribiéndose de tal forma en un continuum histórico de violencias hacia las comunidades y poblaciones que han tratado de escapar de una forma u otra al control del Estado chileno.

Estas representaciones territoriales se pueden yuxtaponer, cuando se trata, por ejemplo, de la implementación de programas de educación intercultural y bilingüe en comunidades conocidas por sus reivindicaciones, y donde estos últimos se constituyen en dispositivos de producción de subjetividad en torno a la definición de lo cultural que operan al momento de definir el "mapuche bueno" y distinguirlo del "enemigo interno" o "terrorista" (Leppe, 2018). Por consiguiente, es muy relevante indicar que, para entender los conflictos actuales y, en particular, los procesos de criminalización, no solo es necesario comprender la historia de usurpación y violencia hacia el Pueblo Mapuche, sino también considerar las políticas indígenas actuales como la continuidad de discursos y prácticas de "pacificación" hacia parte de la colectividad que aún se considera como rebelde por oponerse a programas de desarrollo, generalmente diseñados de forma unilateral desde Santiago. Es, sin duda, en estos últimos años que esta conexión entre políticas públicas, criminalización y permanencia de imaginarios coloniales se ha hecho más patente, al constatar, por ejemplo, que programas de desarrollo como el "Plan Impulso"4 venía de la mano con estrategias policiales, tal como ocurre con el Comando Jungla.

${ }^{4} \underline{\text { http://planimpulso.cl/ }}$ 


\section{El caso Huracán y el uso de la Ley de Inteligencia contra personas inocentes}

La Reforma Procesal Penal implementada en la Región de La Araucanía, marca la transición desde un modelo criminal inquisitivo a uno de corte acusatorio, siendo uno de sus objetivos principales el asegurar la objetividad en la investigación penal y la imparcialidad del juez al dictar sentencia, mediante la separación de funciones de instrucción, acusación y juzgamiento. En este contexto surge la figura del Ministerio Público, organismo autónomo encargado de dirigir la investigación criminal, labor que ha sido catalogada de carácter policial represiva, pues investiga y persigue a los que supuestamente violentan el orden público penal, siendo el cumplimiento de su función la que entrega al sistema la cualidad de imparcialidad (Gandulfo, 1999:421).

Sin embargo, durante los últimos años hemos visto como las actuaciones de este organismo han sido fuertemente cuestionadas a raíz de distintos hechos que han salido a la luz, los cuales han generado un quiebre de este ideario de objetividad y de profesionalismo en el cumplimiento de su función legal ${ }^{5}$.

Sin duda, hasta hace unos años atrás, el hablar de "montajes" e "implantación de pruebas" era visto como si fueran consignas y argucias de defensa en procesos penales, alegaciones que no

${ }^{5}$ Así, por ejemplo, las denuncias efectuadas en abril de este año por el Fiscal Sergio Moya contra el Fiscal Regional de O'Higgins, Emiliano Arias, debido a irregularidades administrativas y posibles delitos de obstrucción a la investigación, han aumentado las críticas hacia el Ministerio Público, las cuales han apuntado directamente hacia la falta de liderazgo y de control del Fiscal Nacional Jorge Abbott. Otra opinión han expresado especialistas como el jurista Mauricio Duce, quien fue parte del equipo que diseñó la Reforma Procesal Penal en el año 1996, quien ha apuntado, además, a la excesiva autonomía del Ministerio Público originada por las distintas leyes que se han aprobado el último tiempo, las cuales han quitado control a los Tribunales de Justicia, por ejemplo, en lo que respecta a las facilidades para solicitar medidas cautelares, limitar el peso de Jueces de Garantía para decretar ilegales las detenciones y disminuir los sistemas de control para medidas intrusivas, entre otras. Ver "De la autonomía a la falta de control: Lo que reveló la crisis en la Fiscalía de Rancagua. Crónica de Gerardo Gómez y Ana María Sanhueza". Abril 2019. En "Pauta". Disponible en:

https://www.pauta.cl/cronica/autonomia-y-falta-del-control-revela-crisis-fiscaliarancagua 
encontraban eco en las instituciones encargadas de impartir justicia ${ }^{6}$. En la Macro Región Sur estas situaciones fueron denunciadas en varias oportunidades, en el contexto de la persecución a distintos dirigentes del movimiento político mapuche mediante la aplicación de la Ley sobre Conductas Terroristas No18.314. Un ejemplo es lo ocurrido en algunos de los casos iniciados en el año 2009 (Caso Tur Bus ${ }^{7}$, Caso Peaje Quino ${ }^{8}$ ) a raíz de las declaraciones prestadas por Raúl Castro Antipán en calidad de testigo de identidad reservada, las que originaron la detención e imposición de prisión preventiva a varios líderes y activistas mapuche de comunidades en procesos de reivindicación territorial ${ }^{9}$. Posteriormente se descubrió que dicho sujeto en realidad era un infiltrado de las policías, siendo en consecuencia, un imputado que finalmente se acogió a la figura de la delación compensada ${ }^{10}$. Él fue el único declarado culpable de los delitos por los cuales se había acusado en dichas causas, transformándose hasta el año 2018, en el único condenado por delito terrorista desde la entrada en vigencia de la Reforma Procesal Penal (Villegas, 2018) ${ }^{11}$.

Las consecuencias de la abucheada Operación Huracán marcan un antes y un después en la historia de los procesos judiciales en La Araucanía, ya que por primera vez se habla derechamente de montaje

\footnotetext{
6 Ejemplo claro de ello es el "Caso Bombas", donde a pesar de resultar absueltos los seis imputados, y de los fuertes cuestionamientos a la investigación dirigida por el Fiscal Alejandro Peña, el Tribunal únicamente apuntó a violaciones del debido proceso, sin confirmar la tesis del "montaje" (RIT 138-2012, Tribunal de Juicio Oral en lo Penal de Santiago).

${ }^{7}$ RIT 99-2013, Tribunal de Juicio Oral en lo Penal de Temuco.

8 RIT 58-2012, Tribunal de Juicio Oral en lo Penal de Angol; RIT 91-2013 Tribunal de Juicio Oral en lo Penal de Angol.

9 Dentro de ellos se encontraban Luis Tralcal Quidel y José Tralcal Coche, actualmente condenados por el Caso Luchsinger Mackay.

${ }^{10} \mathrm{El}$ art. $4^{\circ}$ de la Ley 18.314 dispone la posibilidad de disminuir la pena asignada al delito que se tratare, respecto de aquellos que "dieren informaciones o proporcionaren antecedentes que sirvieren efectivamente para impedir o prevenir la perpetración de otros delitos terroristas, o bien, para detener o individualizar a responsables de esta clase de delitos".

${ }^{11}$ Esta situación cambió con la condena a Juan Flores por colocación de artefacto explosivo, de carácter terrorista, la cual fue confirmada por la Corte Suprema en junio del 2018, en el caso denominado "Escuela Militar" o "Caso Bombas II".
} 
para describir lo ocurrido en ella ${ }^{12}$. Algunos de los protagonistas de las causas mencionadas en los párrafos anteriores hoy están involucrados en la Operación Huracán, en particular, el fiscal del Ministerio Público Sergio Moya Domke y el Mayor (R) de Carabineros Patricio Marín Lazo, quienes actualmente ostentan la calidad de imputados en este caso.

La Operación Huracán inicia judicialmente el 23 de septiembre de 2017, con la autorización dada por la jueza de Garantía de Temuco, Luz Mónica Arancibia Mena para detener a 10 personas, todos dirigentes, autoridades y activistas de la causa mapuche, y para realizar diligencias de entrada y registro en sus respectivos domicilios. La autorización judicial fue otorgada en base a antecedentes que habría obtenido Carabineros de Chile, a través de la Unidad de Inteligencia Operativa Especializada (UIOE Araucanía), consistente en interceptaciones de conversaciones de las aplicaciones Whatsapp, Telegram, Facebook y correo electrónico, que daban cuenta de antecedentes que los vincularía a delitos sucedidos en la región y de una coordinación para llevarlos a cabo, lo cual sería constitutivo de una asociación ilícita de carácter terrorista. Sin embargo, estos antecedentes habían sido obtenidos en virtud de la aplicación de la Ley de Inteligencia $\mathrm{N}^{\circ} 19.974$, ley especial que permite la intervención de comunicaciones siempre que exista autorización del Ministro de Corte de Apelaciones de la jurisdicción correspondiente pero que, a la vez, establece como limitación que la información obtenida mediante su aplicación no pueda ser utilizada como prueba en juicio, a menos que, a su vez, cumpla con las exigencias del Código Procesal Penal ${ }^{13}$. El

12 En el "Informe de la Comisión Especial Investigadora de la actuación de los organismos policiales, de persecución criminal y de inteligencia en torno a la supuesta existencia de pruebas falsas en el marco de la denominada "Operación Huracán" de la Cámara de Diputados se utiliza 29 veces la palabra montaje, resaltando lo señalado en la conclusión 2.5 que reza "En sintesis la Comisión concluye, en función de todos los elementos recabados y que son de público conocimiento, que la utilización de pruebas falsas u obtenidas fraudulentamente en el marco Operación Huracán fue un montaje llevado a adelante por la Unidad de Inteligencia de Carabineros para incriminar a personas pertenecientes al pueblo mapuche".

${ }^{13}$ La Comisión Investigadora Operación Huracán de la Cámara de Diputados de Chile, en su texto "Conclusiones y recomendaciones: primera aproximación" lo entiende en el mismo sentido en su punto 9, disponible en 
motivo de esta limitación radica precisamente en la finalidad de esta ley especial, la cual no es otra que llevar acciones de inteligencia destinadas a entregar información al Estado de Chile con el objetivo de proteger la Seguridad Nacional y preservar el orden constitucional y de contrainteligencia para neutralizar acciones que vayan en contra de estas $^{14}$.

Para entender la gestación de la Operación Huracán, debemos remitirnos al Informe Policial $\mathrm{N}^{\circ} 130$ de la UIOE, informe que fue entregado por la Agencia Nacional de Inteligencia al Ministerio Público el 20 de septiembre de 2017 y que contenía información obtenida mediante intervenciones telefónicas que habían sido autorizadas por el ministro de la Corte de Apelaciones de Temuco, Aner Padilla Buzada15. El informe fue complementado el mismo día en que se realizó la audiencia de formalización, con el informe $\mathrm{N}^{\circ} 346^{16}$, documento que contenía antecedentes que acreditaban las identidades de los supuestos interlocutores de las conversaciones de mensajería, basándose en fuentes abiertas, tales como el sitio informativo Emol, la enciclopedia libre Wikipedia o la red social Facebook.

En el Informe N¹30 se atribuyó falsamente la existencia de mensajes que daban cuenta de la coordinación entre distintas personas con la finalidad de cometer actos ilícitos, consistentes en incendios ocurridos en las regiones del Biobío, La Araucanía y Los Ríos, los que, según el

https://www.camara.cl/pdf.aspx?prmID=151246\&prmTIPO=DOCUMENTOC OMISION

${ }^{14} \mathrm{El}$ art. $2^{\circ}$ de la Ley 19.974 define inteligencia como "el proceso sistemático de recolección, evaluación y análisis de información, cuya finalidad es producir conocimiento útil para la toma de decisiones"; y, contrainteligencia como "aquella parte de la actividad de inteligencia cuya finalidad es detectar, localizar y neutralizar las acciones de inteligencia desarrolladas por otros Estados o por personas, organizaciones o grupos extranjeros, o por sus agentes locales, dirigidas contra la seguridad del Estado y la defensa nacional".

15 No existe claridad desde cuando se llevaron a cabo dichas intervenciones, sin embargo, se ha llegado a la conclusión de que inician, al menos, desde el 2016. Estas intervenciones se realizaron a alrededor de 60 teléfonos, afectando a numerosas personas, entre las cuales podemos encontrar dirigentes y autoridades mapuche, artistas, periodistas y abogados defensores.

16 A diferencia del informe $\mathrm{N}^{\circ} 130$, que era liberado por la Agencia Nacional de Inteligencia y, por lo tanto, bajo esta ley, el Informe $\mathrm{N}^{\circ} 346$ se realiza utilizando la ley común. Con este último se intenta corroborar lo expuesto en el primer informe. 
Ministerio Público, configuraría el delito de Asociación Ilícita Terrorista y el de Incendio Terrorista. Además, un hecho que no ha sido lo suficientemente difundido es que en dichos informes se atribuía a tres adolescentes entre 16 y 17 años la comisión de diferentes delitos, incluyendo su participación en la supuesta asociación ilícita terrorista. Sin embargo, estos no fueron formalizados. Una posible explicación a la exclusión de los adolescentes de la formalización podría tener fundamento en las modificaciones legales realizadas a la Ley 18.314 en los años 2010 y 2011, las cuales excluyen expresamente a los menores de 18 años de la aplicación de esta ley especial ${ }^{17}$.

Actualmente, la defensa de los imputados por la inoculación de mensajes falsos insiste en que ellos solo creyeron en las herramientas tecnológicas que fueron presentadas por uno de los imputados en la causa, el denominado "Profesor" Alex Smith. Sostienen que nadie sabía que este tipo de intervención no podía llevarse a cabo debido a las características de las aplicaciones supuestamente hackeadas ${ }^{18}$.

Por su parte, el Ministerio Público mantiene la misma tesis, declarando que su convencimiento obedeció a la información entregada por Carabineros de Chile y la confianza institucional depositada en ellos. No obstante, desde la primera presentación de las pruebas de parte de los fiscales Cristian Paredes, César Schibar, Roberto Garrido y Felipe González, en la audiencia de formalización, se cuestionaron -por parte de las defensas- los informes, métodos de obtención y la legalidad de aquellas pruebas.

Tiempo después, el Ministerio Público recibió nuevos análisis de los teléfonos supuestamente intervenidos, los cuales fueron practicados por la Unidad Especializada en Lavado de Dinero, Delitos Económicos y Crimen Organizado de la Fiscalía Nacional, cuyo informe concluyó que se inoculó prueba al interior de los teléfonos,

${ }^{17}$ Cabe destacar que estas modificaciones a la Ley sobre Conductas Terroristas son una consecuencia directa de la larga huelga de hambre llevada a cabo por 38 presos políticos mapuche recluidos en distintos recintos carcelarios de las regiones del Biobío, La Araucanía y Los Ríos, durante el año 2010.

${ }^{18}$ Las aplicaciones de mensajería instantánea Whatsapp y Telegram funcionan bajo un cifrado de extremo a extremo que no permite su interceptación según las páginas web de dichas aplicaciones. https://faq.whatsapp.com/es/general/28030015/ y https://telegram.org/faq\#q-do-you-process-data-requests 
mediante la incorporación de mensajes falsos en sus archivos. En virtud de dicho antecedente, el Ministerio Público solicitó, el 24 de enero de 2018, audiencia para comunicar la decisión de no perseverar en la investigación respecto de quienes fueron formalizados por estos delitos, asegurando en dicha audiencia, que habían actuado con total observancia del principio de objetividad y que la posibilidad de la existencia de nuevos delitos derivó en que se agilizaran las solicitudes de órdenes de detención. Sin embargo, la Ley Orgánica Constitucional del Ministerio Público determina las funciones de este órgano, sin contemplar dentro de ellas la prevención del delito. Esto, porque dicha función está asignada a otras instituciones públicas, por tanto, lo que ocurrió en este caso fue un adelantamiento de la punibilidad, llegando al absurdo de investigar delitos que nunca se cometieron y que ni siquiera se encontraban en planificación.

Actualmente, los efectos dañinos respecto de las falsas acusaciones son inconmensurables, pues quienes son investigados mediante el uso de la Ley de Inteligencia tienen la característica de ser considerados un peligro para la seguridad de la nación, con todo lo que ese estigma significa. Así lo dejaba en claro el expresidente Ricardo Lagos, en el mensaje presidencial que inicia el proyecto de ley sobre Sistema de Inteligencia del Estado, indicando que dicho proyecto pretendía "contribuir a que el Estado chileno mejore su capacidad de inteligencia, con el objeto de poder enfrentar y resolver, de mejor modo, los desafíos que pueden amenazar la seguridad del país, la estabilidad institucional y el régimen democrático"19, dejando en claro el fuerte contenido político que acarrea su aplicación. En definitiva, la intervención de comunicaciones mediante esta ley, así como las acciones de seguimiento, no tienen como objetivo la investigación y persecución de hechos delictivos, sino que únicamente buscan obtener la mayor cantidad de información respecto de personas y organizaciones que son consideradas como un peligro para el Estado y el régimen institucional. Dentro de estas amenazas se encuentra, precisamente, la lucha de los pueblos indígenas, tal como lo indicaba

19 "Mensaje de S.E. el Presidente de la República con el que se inicia un proyecto de ley sobre el sistema de inteligencia del Estado y crea la Agencia Nacional de Inteligencia".10 de octubre de 2001. En Historia de la Ley $N^{0} 19.974$ Sobre sistema de inteligencia del Estado y crea la Agencia Nacional de Inteligencia. Disponible en https://www.bcn.cl/historiadelaley/historia-de-la-ley/vista-expandida/5667/ 
en el año 2004 el director de la Agencia Nacional de Inteligencia, al señalar como parte de las preocupaciones de dicho organismo, el estudio del "comportamiento de los movimientos étnicos", además de las cuestiones relativas a la energía y el medio ambiente (Vera Lama, 2017:163-164). En consecuencia, la elección de dirigentes, autoridades y activistas mapuche para la aplicación de dicha normativa se basa en la visión que tiene el Estado del mapuche como "enemigo interno" o amenaza y peligro para la estabilidad institucional, lo que incluye el modelo económico, debido a la enérgica e histórica lucha que se ha llevado cabo para la reconstrucción territorial y cultural, y la defensa y oposición frente a las políticas extractivistas que se han pretendido implementar en su territorio ${ }^{20}$.

\section{Muerte e impunidad en el Wallmapu: el Comando Jungla}

El 28 de junio de 2018 el presidente Sebastián Piñera anunciaba la creación de un grupo especial de Carabineros, formado y preparado para el combate eficaz del terrorismo en la Región de La Araucanía ${ }^{21}$. Dicho grupo especial fue denominado "Comando Jungla", debido al entrenamiento que algunos de sus miembros habían realizado en Colombia para aprender técnicas que permitieran enfrentar a fuerzas guerrilleras altamente armadas y con una realidad política y militar absolutamente distinta a la que se vive en el sur del país. En efecto, los Comandos Jungla o simplemente JUNGLA, son parte de la Policía Nacional de Colombia, encargados de planear y ejecutar operaciones contra el narcotráfico, las bandas criminales y el crimen organizado, los cuales fueron creados entre los años 2000 y 2008 con ayuda del Departamento de Estado de los Estados Unidos que los equipó y entrenó como parte del Plan Colombia ${ }^{22}$. Desde el punto de vista

\footnotetext{
20 La implementación del modelo extractivista es una de las manifestaciones de violencia más profundas que persisten contra el pueblo mapuche. El Estado y el modelo de desarrollo extractivista obstruyen el bienestar subjetivo, socioeconómico y ambiental de las comunidades, en lo que se conoce como "violencia estructural". (Bresciani y otros, 2019:143)

${ }^{21}$ https://www.soychile.cl/Temuco/Policial/2018/06/28/541938/Grupoantiterrorista-de-Carabineros-fue-anunciado-por-el-presidente-Pinera-enTemuco.aspx

22 https://www.policia.gov.co/especializados/jungla
} 
simbólico, la elección de nombrar "Comando Jungla" a esta unidad especializada refleja la persistencia de una geografía imaginaria y racista en base a políticas decimonónicas de colonización e invasión militar del territorio mapuche que representaban a los mapuche como "indios malos en tierras buenas" (Casanueva, 1998) o furtivos en medio de "montes" y "selvas vírgenes" (Le Bonniec, 2014b).

La creación de esta Unidad Especializada estuvo acompañada de una gran inversión económica para la compra de armas, vehículos y tecnología de punta, como correlato del aumento exponencial que ha experimentado el gasto policial desde el año 2009 a la fecha, lo que ha ocurrido principalmente en las provincias de Malleco y de Arauco (Rojas Pedemonte y Miranda, 2015:51). Así lo relataba el propio presidente Sebastián Piñera, en la presentación de la Unidad Especial, al indicar que el equipo de efectivos policiales "ha sido preparado y formado para combatir con eficacia el terrorismo y cuenta con los mejores instrumentos y herramientas tecnológicas, como drones, sistemas de comunicación, sistemas de inteligencia, para poder cumplir con eficacia su rol"'23.

Las fatídicas consecuencias de la implementación de este grupo en La Araucanía fueron advertidas desde sus primeros meses por las propias comunidades mapuche, haciendo eco también en algunas autoridades políticas que indicaban que la creación del Comando Jungla no ayudaba a lograr la paz, sino por el contrario, contribuía a reprimir al Pueblo Mapuche en la zona y que el único aporte de este grupo había sido aumentar la violencia en La Araucanía 24. Estas apreciaciones contaban con el sustento dado por la multiplicidad de casos de violencia policial conocidos en el último tiempo y que ha afectado principalmente a miembros de comunidades en procesos de reivindicación territorial. Solo a modo ejemplar, el Instituto Nacional de Derechos Humanos (INDH) ha interpuesto diversos recursos de

\footnotetext{
${ }^{23}$ https://www.interior.gob.cl/noticias/2018/06/28/gobierno-presenta-grupofuerza-especial-de-tarea-de-carabineros-contra-el-terrorismo/

${ }^{24}$ Declaraciones de la Diputada Mapuche-Williche Emilia Nuyado y del Presidente de la Asociación de Municipalidades con Alcalde Mapuche (AMCAM), Juan Carlos Reinao, en:

https://radio.uchile.cl/2018/07/31/a-un-mes-de-su-implementacion-el-comandojungla-aun-no-ha-mostrado-resultados/
} 
amparo $^{25}$ para denunciar procedimientos policiales violentos e ilegales contra personas mapuche. En su amplia mayoría, dichos recursos han sido acogidos (al menos 17 entre 2012 y 2018), quedando demostrado que el actuar de Carabineros no se ajusta a los estándares constitucionales e internacionales que deben regir el uso de la fuerza pública. Sin embargo, pese a este reconocimiento respecto a la continua vulneración de derechos fundamentales, los hechos continúan repitiéndose, afectando con ello la vida e integridad de muchas personas mapuche, incluyendo niños, niñas y adolescentes, los que, en general, permanecen en la impunidad.

En consecuencia, la muerte de Camilo Catrillanca, nieto del lonko de la Comunidad Temucuicui, acaecida el día 14 de noviembre de 2018, no puede sino calificarse como la crónica de una muerte anunciada. En dicha oportunidad, un gran contingente policial llevó a cabo un procedimiento en el Lof Temucuicui -comunidad que ha sido objeto de múltiples procedimientos policiales violentos en los últimos añospresuntamente para detener a los supuestos responsables del robo de unos vehículos denunciado esa misma tarde. Dicho allanamiento terminó con la muerte del joven mapuche de 24 años debido a un disparo de Carabineros, y la violenta detención y posterior imputación

25 Todos los hechos que motivaron los recursos de amparo llevados a cabo por el INDH tuvieron resolución de la Corte de Apelaciones de Temuco, y en algunos casos aun de la Corte Suprema: Resolución de la Corte de Apelaciones de Temuco de fecha 3 de septiembre del 2012, rol 604-2012; Corte de Apelaciones de Temuco, 20 de diciembre del 2012, rol 838-2012; Corte de Apelaciones de Temuco, 7 de diciembre del 2012, rol 907-2012; Corte de Apelaciones de Temuco, 6 de julio del 2013, rol 435-2013; Corte de Apelaciones de Temuco, 31 de enero del 2014, rol 982-2013; Corte de Apelaciones de Temuco, 26 de agosto del 2014, rol 569-2014; Corte de Apelaciones de Temuco, 17 de octubre del 2014, rol 741-2014; Corte de Apelaciones de Valdivia, 21 de octubre del 2014, rol 203-2014; Corte de Apelaciones de Temuco, 31 de enero del 2015, rol 1144-2014; Corte de Apelaciones de Temuco, 26 de febrero del 2016, rol 78-2016; Corte de Apelaciones de Temuco, 25 de mayo del 2016, rol 493-2016; Corte de Apelaciones de Temuco, 26 de julio del 2017, rol 134-2017; Corte de Apelaciones de Temuco, 25 de mayo del 2017, rol 67-2017; Corte de Apelaciones de Temuco, 20 de junio del 2017, rol 74-2017; Corte de Apelaciones de Temuco, 10 de abril del 2017, rol 46- 2017; Corte Suprema, 4 de abril del 2018, rol 5427-18; Corte Suprema, 30 de mayo del 2018, rol 10868-2018. 
del joven de 15 años que lo acompañaba, quien sobrevivió a la ráfaga de disparos ${ }^{26}$.

De este modo, a solo cinco meses de su presentación pública, el Comando Jungla ya contaba con un joven mapuche muerto en sus registros, que viene a engrosar la larga lista de mapuche muertos a manos de agentes del Estado chileno. Estos homicidios son solo la punta del iceberg que evidencia el desprecio hacia una forma de vida y una manera distinta de apreciar la realidad que se opone sustancial y materialmente a las concepciones de desarrollo impulsadas por los distintos gobiernos de este país. Esta "violencia neocolonial", que niega al mapuche como un otro válido, particular y diverso, y que también lo niega como sujeto político y colectivo, es una de las más graves, pues se resiste a la posibilidad de que este pueblo se manifieste y decida por sí mismo, y que se autodetermine (Bresciani y otros, 2019:144). Al efecto, cabe destacar la forma en que el Gobierno presentó en su momento al denominado "Comando Jungla" de Carabineros. En la página web oficial del Ministerio del Interior se indica:

Tanto el presidente Piñera como el Ministro del Interior hicieron un llamado de esperanza para la región que, debido a los hechos de violencia sufridos los últimos años, ha visto desaprovechado el potencial de desarrollo, a la vez que la inversión extranjera desapareció. "Hay un nuevo repertorio de esperanza, de expectativa, de levantar La Araucanía como se lo merece y en eso estamos empeñados. Eso demuestra la voluntad del Gobierno de sacar adelante a la región", aseguró el ministro Andrés Chadwick ${ }^{27}$.

La violencia estatal se refleja también en la aplicación sistemática de un derecho penal del enemigo, mediante la invocación de leyes penales agravadas, como la Ley de Seguridad Interior del Estado y, desde el

\footnotetext{
${ }^{26}$ EMOL, Desde el operativo de Carabineros hasta la salida de seis de ellos: Los cinco días tras la muerte de Camilo Catrillanca. Fuente:

https://www.emol.com/noticias/Nacional/2018/11/18/927785/Cronologia-delCaso-Catrillanca.html

${ }^{27}$ https://www.interior.gob.cl/noticias/2018/06/28/gobierno-presenta-grupofuerza-especial-de-tarea-de-carabineros-contra-el-terrorismo/
} 
año 2000, de la Ley 18.314 sobre Conductas Terroristas. Esta situación suma una nueva calificación del mapuche por parte del Estado: el de "enemigo", lo que, según Villegas, se debe a que "su forma de vida, su forma de producción, su cultura y su religión no son compatibles con la acumulación capitalista" y porque "habiendo agotado los cauces de resolución de conflicto, optó por la utilización de la violencia contra la propiedad privada" (2009:39). La creación del Comando Jungla entronca de manera indisoluble con esta política de Estado. Justamente, la finalidad de dicha Unidad Especializada es el combate contra el supuesto "terrorismo" existente en La Araucanía. La recurrente invocación de la Ley 18.314 sobre conductas terroristas, tanto por el Ministerio Público como por los gobiernos de turno, para la persecución de delitos asociados a la reivindicación territorial mapuche, constituye el sustento material -objetivo y subjetivo- para la creación y operatividad de esta violencia institucionalizada hacia las comunidades mapuche movilizadas para recuperar su territorio histórico.

El fallo del Tribunal Oral en lo Penal de Temuco en el caso Luchsinger Mackay (Causa RIT 150-2017) es una muestra concreta de dicha realidad. Los jueces Germán Varas Cicarelli, Rocío Pinilla Debaddie y Mauricio Poblete Erices decidieron condenar a los comuneros mapuche José Tralcal Coche, Luis Tralcal Quidel y José Peralino Huinca como autores del delito de incendio con resultado de muerte de carácter terrorista. Esto pese a la existencia de dos juicios previos que, ponderando las mismas pruebas, ya habían calificado los mismos hechos como delito común, es decir, no terrorista. Uno de ellos inclusive confirmado por la Corte Suprema ${ }^{28}$.

${ }^{28}$ El primer Juicio Oral llevado a cabo tras la muerte del matrimonio Luchsinger Mackay fue el seguido contra el Machi Celestino Córdova, donde el Tribunal Oral en lo Penal de Temuco calificó los hechos como incendio con resultado de muerte, desechando la calificación terrorista (Causa RIT 114-2013). Dicha sentencia fue luego confirmada por la Corte Suprema. El segundo Juicio Oral en este caso (Causa RIT 150-2017) fue seguido en contra de Luis Tralcal, José Tralcal, José Peralino, la machi Francisca Linconao y otros 7 dirigentes mapuche de la comuna de Padre las Casas. En dicha oportunidad, el Tribunal Oral de Temuco absolvió a todos los imputados, calificando los hechos nuevamente como incendio con resultado de muerte, sin calificarlos terrorista (Sentencia de 14 de noviembre de 2017). Dicha sentencia fue anulada por la Corte de Temuco (Rol 1056-20187), quien dispuso la 
Pese a que con fecha 10 de octubre de 2018, la Corte Suprema recalificó los hechos descartando -nuevamente- el carácter terrorista, lo cierto es que, para una parte de los jueces regionales, la sola asociación de determinados delitos a las reivindicaciones territoriales mapuche es suficiente para calificar los hechos como actos terroristas. En tal contexto, la invocación de la Ley 18.314 sobre conductas terroristas y su sobre uso, sin mayor resultado en término procesal, se ha vuelto claramente política, al instaurar estados de excepción en ciertos sectores del sur del país, estigmatizando su población, quitándole garantías legales e instaurando de forma equívoca el concepto de terrorismo en la sociedad chilena.

¿Qué se puede esperar de la unidad de Carabineros creada para el combate del terrorismo? ¿Qué explicación existe para el hecho de que una unidad especializada en terrorismo participe en la persecución de unos supuestos ladrones de vehículos? El desarrollo de la investigación por parte de la Unidad de Derechos Humanos de la Fiscalía de Temuco, ha permitido esclarecer la sucesión de hechos que terminó con la vida del joven Catrillanca y, además, las graves afectaciones sufridas por el adolescente de iniciales M.A.P.C. que lo acompañaba mientras se trasladaban en el tractor de la Comunidad Temucuicui. Justamente, producto de las diligencias investigativas, ha quedado demostrada la política institucionalizada en Carabineros de Chile que pretendió encubrir el uso indiscriminado de armamento de guerra ${ }^{29}$, la muerte de una persona y las torturas sufridas por un adolescente mapuche, quién además se constituyó como el único testigo presencial de la violencia estatal y pieza clave en el descubrimiento de la verdad. Como consecuencia de ello, tras el cierre de la investigación, la acusación ha sido presentada no solamente en contra de los autores directos del homicidio de Camilo Catrillanca y de las torturas y del homicidio frustrado del adolescente M.A.P.C., sino que también ha

realización de otro Juicio Oral, el cual terminó con condena de José Tralcal, a Luis Tralcal y a José Peralino (Sentencia de fecha 11 de junio de 2018).

${ }^{29}$ La investigación ha determinado que los imputados Carlos Alarcón y Raúl Ávila dispararon más de 10 tiros en total con una Carabina Colt M-4, calibre 5,56mm, que portaban como parte del armamento de servicio. Dicho fusil de uso bélico, ha sido utilizado por las fuerzas armadas estadounidenses y se destaca por su precisión, tal como se indica en la página web del fabricante: https://www.colt.com/detailpage/colt-le6920-carbine-223556-161-301-pmag-mbus-4-pos-stk-blk 
abarcado a otros seis funcionarios de Carabineros, incluyendo a los mandos regionales de Fuerzas Especiales, del Grupo de Operaciones Policiales Especiales (GOPE) y al abogado de la Institución ${ }^{30}$.

Como es de público conocimiento, las primeras comunicaciones oficiales emanadas desde Carabineros de Chile afirmaron que, durante la acción policial que iba tras los supuestos autores del robo de tres vehículos, fueron atacados por desconocidos. Por esta razón, sostienen que decidieron hacer uso de sus armas de fuego para realizar disparos disuasivos y controlados, y que el tractor conducido por Camilo Catrillanca se habría cruzado en la línea de fuego. Esta versión fue rápidamente respaldada por el mando civil, partiendo por el mismo presidente de la República ${ }^{31}$ y el entonces intendente de La Araucanía, Luis Mayol. Este último fue uno de los primeros en dar declaraciones tras los fatídicos hechos, agregando a la versión institucional de Carabineros, que la víctima Catrillanca contaba con antecedentes penales por receptación ${ }^{32}$. Sin embargo, estas circunstancias fueron desmentidas por la evidencia recopilada, que permitió determinar que los disparos se habían percutido sin provocación alguna y que la orden de falsear la información, así como de ocultar y destruir los registros audiovisuales del procedimiento, emanó desde la superioridad de la policía uniformada, tal y como fue reconocido por el autor material del crimen, Carlos Alarcón, en un video difundido por las redes sociales donde indicaba que fue obligado a mentir ${ }^{33}$. Asimismo, la existencia de condenas previas a Camilo Catrillanca fue totalmente descartada, luego de que se propagara públicamente su extracto de filiación y antecedentes ${ }^{34}$.

A esto hay que agregar la detención del único testigo civil de lo ocurrido el 14 de noviembre de 2018: M.A.P.C. El adolescente de 15

30 Acusación presentada con fecha 26 de junio de 2019, en contra de Carlos Alarcón Molina, Patricio Sepúlveda Muñoz, Braulio Valenzuela Aránguiz, Raúl Ávila Morales, Gonzalo Pérez Vargas, Jorge Contreras Figueroa, Manuel Valdivieso Terán y Cristian Inostroza Quiñiñiir.

31 https://www.cnnchile.com/pais/pinera-respalda-a-carabineros-y-reivindica-suderecho-a-defenderse-cuando-son-atacados 20181115/

32 https://www.latercera.com/nacional/noticia/intendente-la-araucania-confirmajoven-mapuche-formaba-parte-del-grupo-robo-tres-vehiculos/402296/

33 https: / / www.youtube.com/watch? $\mathrm{v}=\mathrm{v}-\mathrm{v} 8 \mathrm{x} 35 \mathrm{aJK} 0$

${ }^{34}$ https://www.eldesconcierto.cl/2018/11/16/registro-de-antecedentes-penalesde-camilo-catrillanca-comprueba-falsedad-de-dichos-de-luis-mayol-y-hermes-soto/ 
años, tras sobrevivir a la ráfaga de disparos propinadas por los funcionarios del GOPE, fue detenido violentamente y golpeado mientras su acompañante se encontraba aún agonizando en el tractor $^{35}$. Posteriormente, el Ministerio Público decidió formalizarlo por un supuesto delito de receptación de vehículo motorizado, sin embargo, tras meses de investigación, el 4 de abril de 2019, el ente persecutor comunicó la decisión de no perseverar en la investigación ${ }^{36}$. Cabe recordar que los homicidios de Alex Lemún, Matías Catrileo y Jaime Mendoza Collío, tuvieron exactamente la misma dinámica. Carabineros de Chile, una vez producida la muerte de estos jóvenes mapuche, justificó el actuar en supuestos enfrentamientos armados, versión que posteriormente fue respaldada por el poder civil, todo lo cual fue finalmente desmentido por las investigaciones criminales. Solo en el caso de Camilo Catrillanca las responsabilidades se han hecho efectivas más allá del autor directo de los disparos. La Justicia Militar jamás investigó o procesó a quienes intentaron falsear la historia y encubrir a los responsables en los otros tres casos.

35 De acuerdo a lo señalado por la Directora del Instituto de Derechos Humanos en el mes de noviembre de 2018, en el sitio institucional, "El joven presenció el asesinato o la muerte de su compañero. Murió al lado de él. Posteriormente lo bajaron del tractor, lo golpearon, lo ingresaron a un carro policial y lo siguieron golpeando e insultando". Por otra parte, en el mes de julio de 2019 aparece en prensa la acción legal ejercida por la Defensoría de la Niñez, que persigue elevar las condenas a los responsables de las torturas a las que fue sometido el adolescente, refiriendo que "sin que existiera ningún tipo de resistencia al proceder policial, por parte de M.A.P.C., el acusado Ávila Morales se abalanzó sobre el joven, lo lanza al suelo y lo golpeó en diversas partes del cuerpo, obligándolo a permanecer boca abajo en el barro, para después inmovilizarlo atando sus manos con excesiva e injustificada presión, poniendo una de sus piernas sobre su espalda, causándole lesiones físicas consistentes en contusiones costales en el lado izquierdo, cicatriz rosada de 1,55 cm en cara dorsal de la muñeca izquierda y cicatriz costrosa de $3 \mathrm{~cm}$ en la cara lateral de la muñeca izquierda". En entrevista realizada en marzo de 2019 para el canal Chilevisión, el adolescente también reporta que "el ex sargento Ávila lo tuvo de rodillas en el suelo. De rodilla, en todo momento me tuvo de rodillas. (Su rodilla) estaba en mi espalda y (estaba) apuntando aquí, en la cabeza", refiriendo incluso que, al observar cómo cambiaba la tarjeta de memoria, "me quedó mirando y me dijo: “¿qué mirai cabro culiao?, ¿o querí que te mate como a tu peñ̃?".

36 https://www.cooperativa.cl/noticias/pais/region-de-la-araucania/ fiscaliacomunico-decision-de-no-perseverar-en-caso-del-menor-que/2019-04$\underline{05 / 140910 . h t m l}$ 
Ahora bien, la Justicia Militar fue modificada mediante la Ley 20.477 del 10 de diciembre de 2010, la que a su vez fue luego modificada por la Ley 20.968. Esta modificación excluyó a los civiles de la aplicación de la Justicia Militar. Dichas reformas legales tuvieron su origen en las exigencias efectuadas por más de 30 presos políticos mapuche, entre ellos don José Tralcal y don Luis Tralcal, actualmente condenados en el Caso Luchsinger Mackay, y que durante el año 2010 mantuvieron una huelga de hambre en rechazo a la aplicación de la Ley 18.314 sobre Conductas Terroristas, así como al doble procesamiento que estaban siendo llevados adelante tanto por el Ministerio Público como por las Fiscalías Militares. Con dicha modificación legal, el Estado de Chile vino a dar cumplimiento a lo ordenado por la Corte Interamericana de Derechos Humanos al condenar a nuestro país en sentencia de fecha 22 de noviembre de 2005, Caso Palamara Iribarne vs. Chile ${ }^{37}$. Fue justamente esta reforma legal la utilizada por la Corte Suprema para reabrir el caso de Alex Lemún, quitándole la competencia a la Fiscalía Militar y remitiendo los antecedentes al Ministerio Público. Actualmente, la investigación es llevada por la división de DD.HH. de la Fiscalía de Temuco. El carabinero en retiro, Marco Treuer Heysen se encuentra formalizado por homicidio y sujeto a prisión preventiva.

La investigación por la muerte del joven Camilo Catrillanca y las torturas sufridas por el adolescente que lo acompañaba, constituye la primera investigación desarrollada de forma íntegra por la Justicia Civil. Todos los anteriores casos de homicidios de jóvenes mapuche por agentes de Carabineros de Chile han sido tramitados por la Justicia Militar, que ha determinado sanciones desproporcionadamente bajas y exclusivamente respecto del autor material del crimen, dejando en la absoluta impunidad a todos aquellos funcionarios que, tal como en el caso de Camilo Catrillanca, han intentado encubrir el asesinato mediante la aportación de versiones mendaces y/o la alteración de las evidencias. Se espera que la Justicia Civil, a diferencia de la Justicia Militar, permita que en el caso de Camilo Catrillanca y del adolescente M.A.P.C. se establezcan judicialmente las responsabilidades penales correspondientes, imponiendo las penas proporcionales a la gravedad

${ }^{37}$ Serie C No 135, identificada bajo el rol CIDH/N 135/2005. 
de los delitos cometidos para que, de esta manera, se propenda a la efectiva reparación de las víctimas y sus familias.

Impacto psicosocial de la criminalización en niñas, niños, adolescentes y jóvenes de comunidades mapuche en resistencia

“...No sé cómo son. ¿Quiénes? Los pacos. ¿No los has visto? No. ¿Cuándo vienen a tu casa? No...Tal vez tú no sabes lo que hay debajo de la ropa y los cascos cuando vienen a tu casa... No pu, si te digo que no sé cómo son...

Debajo de toda esa ropa y los cascos hay personas... ¿En serio?”

(Entrevista a niña mapuche de seis años, mientras dibujaba un allanamiento vivido en su comunidad. Enero de 2010)

El año 2015, el Comité de los Derechos del Niño de Naciones Unidas, en sus Observaciones Finales del Examen Periódico a Chile, explicita su preocupación acerca de la desigualdad, la discriminación y la violencia de las que son víctimas los niños de pueblos originarios, particularmente del Pueblo Mapuche. Agrega que "teniendo en cuenta su Observación General núm. 11 (2009) sobre los niños indígenas y sus derechos en virtud de la Convención", insta al Estado parte a modificar aquellos aspectos que generan condiciones estructuralmente violentas, así como "conseguir el acceso" de los niños y las niñas a servicios sociales básicos, salud y educación, sin discriminación alguna. El Comité insta también al Estado chileno para que "actúe de inmediato para acabar con la violencia policial de todo tipo contra los niños indígenas y sus familias, también en el contexto de las actividades de desarrollo" (Comité de los Derechos del Niño, 2015: 19).

La violencia policial utilizada para reprimir a las comunidades mapuche que demandan derechos territoriales y políticos cumple una doble función. Por un lado, la disputa del control territorial con las comunidades que avanzan en sus procesos de autodeterminación, y por otro, el de ejecutar órdenes judiciales con operativos violentos e intimidantes, que generan un miedo constante en los miembros más indefensos de las comunidades, entre ellos, niños y niñas (Fernández y Ojeda, 2015). 
Es desde las etapas tempranas de la infancia que niños y niñas mapuche empiezan a dar cuenta del impacto que provocan en ellos el miedo a la pérdida de sus padres por disparos o encarcelamientos arbitrarios, la impotencia y percepción de injusticia frente a los procesos de estigmatización de sus familias y comunidades en el marco de la criminalización de las demandas mapuche, y la instalación de la figura del mapuche como "terrorista" o "delincuente". Una madre mapuche entrevistada es elocuente al respecto ${ }^{38}$ :

"Ellos llegan por ejemplo a las seis de la mañana, los niños se ponen a llorar altiro ¡mamá no te van a matar! y lloran, porque los ven que están armados, que se les puede escapar un tiro...me ha tocado como criarlos solos porque mi marido en cualquier momento se puede ir preso...ella a veces ve un paco y les hace así no más (aprieta los puños) y dice que le da rabia, que han tenido a su papá preso...".

En este sentido, es posible referir un desarrollo evolutivo en un contexto de violencia y estrés psicosocial permanente, con procesos traumáticos acumulativos y complejos, derivados de la ejecución de una política de criminalización de sus comunidades y familiares. Se evidencia una experiencia constante de impunidad respecto de los agentes estatales, y una vivencia subjetiva de injusticia e indefensión, además de una desconfianza progresiva en las instituciones del Estado. Un joven mapuche lo explica con desencanto: “...pa' nosotros nunca va a haber justicia porque nosotros somos mapuche, ellos pueden hacer con nosotros lo que quieran porque nadie les va a hacer nada a ellos"39.

La violencia hacia los mapuche reviste actitudes y acciones racistas, muchas veces deshumanizantes, llegando a configurar el delito de tortura, con situaciones donde las víctimas también son niños y adolescentes ${ }^{40}$. Un ejemplo de lo anterior fue la utilización de la Ley

38 Entrevista madre mapuche, miembro de comunidad afectada por violencia policial, Provincia de Malleco, enero de 2010.

39 Entrevista joven miembro de comunidad afectada por violencia policial, Provincia de Malleco, octubre 2018.

40 https://www.indh.cl/indh-y-defensoria-de-la-ninez-presentan-querella-portorturas-a-adolescente-que-acompanaba-a-camilo-catrillanca/ 
18.314 en procesos contra adolescentes mapuche, situación que se modificó tras la prolongada huelga de hambre de los presos políticos mapuche del año 2010. Entre los años 2008 y 2010, al menos cuatro jóvenes mapuche fueron imputados bajo esa legislación de excepción, siendo finalmente todos absueltos, sufriendo consecuencias como secuelas físicas de gravedad, periodos prolongados de clandestinidad, malos tratos o torturas.

Al considerar las características de la etapa evolutiva, es relevante considerar que los adolescentes mapuche van complejizando y consolidando el conocimiento de sí mismos y de su cultura en este contexto. Este proceso involucra el desarrollo de la identidad étnica y cultural, que comienza a ser explorada, profundizando críticamente la comprensión de lo que significa ser miembro del Pueblo Mapuche en el territorio administrado por el Estado chileno, hasta llegar a sostener un vínculo afectivo que representa la valoración de la relación y pertenencia a su grupo cultural (Jiménez Bustos, 2017). De forma simultánea, los adolescentes y jóvenes complejizan la comprensión de las causas y consecuencias de la represión y el racismo que han experimentado. Pueden conceptualizar estos agravios, características constantes de su relación con el Estado de Chile y sus instituciones, integrando y subjetivando, de esta forma, las experiencias de discriminación y represión vividas. Así, la progresiva participación política de los adolescentes va asociada a una identidad cultural fortalecida, con claridad y sentido crítico con respecto a la relación del Pueblo Mapuche con el Estado chileno, definiéndose a través de la participación en los espacios sociales, ceremoniales y políticos de sus comunidades. El siguiente comunicado es ilustrativo:

"Ya llevamos más de un mes y no se ha hecho nada por nosotros y nos tienen como verdaderos criminales, cuando nuestro único delito es ser MAPUCHE y arrebatan nuestra libertad y la felicidad de nuestras familias...Pero no podrán callar nuestra voz por la injusticia que se comete contra nuestro pueblo por parte de un Gobierno tan cobarde y traicionero, y nos tienen aquí 
injustamente. Entonces cómo quieren que creamos en ellos, si

cada día alimentan nuestros corazones con rabia y dolor" 41 . Como expresión de lo anterior, es posible observar la participación habitual de adolescentes mapuche en actividades comunitarias que tienen como fin la afirmación y reivindicación de derechos políticos, culturales y territoriales, las que deben comprenderse como la búsqueda de mecanismos reivindicativos para la superación de una realidad social que discrimina su cultura, ignora sus necesidades y criminaliza demandas ${ }^{42}$, destruyendo de manera progresiva los contextos en los que se desarrollan. Lo anterior representa un fracaso y una deuda de la sociedad en la generación de condiciones protectoras para los niños, niñas y adolescentes del Pueblo Mapuche.

El derecho de jóvenes y adolescentes al desarrollo de la identidad y personalidad propias, a la participación política, a la justicia y a la vida, se encuentran consagrados en la Convención Iberoamericana de Derechos de los Jóvenes ${ }^{43}$. El Estado de Chile ha incumplido

${ }^{41}$ Movimiento Generación 80. 12 de enero de 2010. Carta Abierta de Cristian Cayupan y Leonardo Quijón. Carta desde la Cárcel para menores de Chol Chol http:/ /www.g80.cl/noticias/columna completa.php? varid=7019

42 Reconocidos teóricos e investigadores - como Barudy (2006)- de los efectos que la violencia social provoca en la infancia, señalan que los procesos de toma de conciencia; simbolización de la realidad familiar y social, por difícil que esta sea, con el objetivo de buscar alternativas de cambio; la participación activa en procesos y redes sociales y comunitarias; la promoción de la participación de niños y adolescentes en actividades que conlleven un compromiso político en búsqueda de una sociedad más justa y no violenta, además de su implicancia en "la lucha contra las situaciones de violencia y de los sistemas de creencias que las sustentan", constituyen recursos naturales positivos que permiten procesos de elaboración y resiliencia.

${ }^{43}$ La Convención Iberoamericana de Derechos de los Jóvenes es el único tratado internacional centrado específicamente en los derechos civiles, políticos, económicos, sociales y culturales de las personas jóvenes entre 15 y 24 años. Fue firmado en la ciudad de Badajoz, España, en octubre de 2005, y entró en vigencia el 1 de marzo de 2008. En su preámbulo señala: "Constatando que los jóvenes conforman un sector social que tiene características singulares en razón de factores psico-sociales, físicos y de identidad que requieren una atención especial por tratarse de un periodo de la vida donde se forma y consolida la personalidad, la adquisición de conocimientos, la seguridad personal y la proyección al futuro. Teniendo en cuenta que entre los jóvenes de la región se constatan graves carencias y omisiones que afectan su formación integral, al privarlos o limitarles derechos como: la educación, el empleo, la salud, el medio ambiente, la participación en la 
sistemáticamente su rol de garante respecto del efectivo ejercicio de estos derechos en el caso de adolescentes y jóvenes mapuche, lo que ha sido reiteradamente denunciado en distintas instancias nacionales e internacionales de derechos humanos (Molina, 2010; Anide, 2011; ROIJ, 2014; Consejo Nacional de Infancia, 2015). Este incumplimiento, como ha sido denunciado, deriva, por una parte, de la discriminación en el acceso a derechos sociales, civiles, económicos y culturales $^{44}$, y por otra, a las consecuencias derivadas de la represión que los poderes del Estado ejercen, como un instrumento de control social asociado a los procesos de criminalización y judicialización del movimiento mapuche. Este último contexto, que opera desde una institucionalidad represiva y negacionista ${ }^{45}$, devela su accionar en montajes como la llamada Operación Huracán, donde se denunció la investigación de adolescentes mapuche en el marco de la Ley de Inteligencia ${ }^{46}$ o en la militarización de la zona de Ercilla, que precedió al asesinato del joven Camilo Catrillanca y al homicidio frustrado del adolescente que lo acompañaba, así como el inmediato encubrimiento de los hechos, que buscaba exculpar a los responsables.

vida social y política y en la adopción de decisiones, la tutela judicial efectiva, la información, la familia, la vivienda, el deporte, la recreación y la cultura en general." p.1

44 De acuerdo al documento "Región de La Araucanía. Casen 2015" del Ministerio de Desarrollo Social “Al año 2015, los datos de la Encuesta Casen, permiten observar que la Región de La Araucanía alcanza el más alto porcentaje de personas en situación de pobreza en el país, diagnóstico que es corroborado tanto a través de la medición por ingresos como a través de la medición multidimensional. Mientras que la medida por pobreza por ingresos revela la presencia de un 23,6\% de personas en situación de pobreza, la medida multidimensional indica una tasa de $29,2 \%$ de población en situación de pobreza". p.3.

45 Según refiere el Dr. Juan Pablo Artinian, el negacionismo, considerado por muchos autores la última etapa de los genocidios, tiene como objetivo negar y ocultar el crimen, exculpando a los perpetradores de su responsabilidad, pudiendo ser cometidos por individuos o por Estados, expresándose tanto a niveles simbólicos como materiales. El impacto del negacionismo representa una doble victimización, la primera durante la realización del crimen y la segunda al negar a la víctima su condición de tal, buscando responsabilizarla de su daño.

46 Ver Poder Judicial Chile. 12 de febrero 2018. Operación Huracán: J. Garantía de Temuco decreta sobreseimiento de imputados en la causa (2). minuto 107 en adelante. En https: / www.youtube.com/watch?v=2qY4B8LJx6Y\&t=8397s

B ANUARI DEL CONFLICTE SOCIAL 2018 
La aparición de acciones de negación, distorsión y ocultamiento de los hechos y la instalación de una narrativa inculpatoria hacia las víctimas ha sido utilizada con anterioridad por la institucionalidad del Estado, vulnerando los derechos de jóvenes y adolescentes mapuche a la vida y la justicia. Contamos con tres casos emblemáticos. Por ejemplo, en noviembre de 2002, el adolescente mapuche Álex Lemún Saavedra, de 17 años, es asesinado de un tiro en la frente por el ex oficial de Carabineros Marco Antonio Treuer, quien en primera instancia es sobreseído el año 2005 por la Corte Marcial argumentando que el ex oficial actuó en defensa propia ${ }^{47}$, siendo finalmente la Comisión Interamericana de Derechos Humanos la que, doce años después, ordena la reapertura de investigación. Posteriormente, el 3 de enero de 2008, el joven mapuche Matías Catrileo Quezada de 23 años, fue asesinado por el Cabo $2^{\circ}$ Walter Ramírez, con un disparo de subametralladora UZI que entró por su espalda y salió por su abdomen. La primera versión oficial sostenida por Carabineros, siendo avalados por el Servicio Médico Legal a través de un informe preliminar, señala que la trayectoria de la bala fue de adelante hacia atrás. Fue tras peritajes realizados por Policía de Investigaciones y pruebas aportadas por testigos del homicidio, que se pudo determinar la ilegalidad del actuar de las instituciones estatales ${ }^{48}$. El año siguiente, el 12 de agosto de 2009, el joven mapuche Jaime Mendoza Collío, de 24 años, fue asesinado de un disparo en la espalda por el Cabo Miguel Jara Muñoz. Como en los casos anteriores, fue en un contexto de recuperación territorial y la versión oficial inmediata fue la legítima defensa del uniformado al ser atacado por los mapuche con armas de

47 El año 2017, la Comisión Interamericana de Derechos Humanos, estableció la "responsabilidad de Chile por la violación a los derechos a la vida, integridad personal, igualdad y no discriminación, derechos del niño, derechos a las garantías judiciales y protección judicial de Alex Lemún, su familia y la comunidad Requén Lemún”. El Estado de Chile comprometió medidas reparatorias, entre ellas, reabrir la investigación y firmar un Decreto Supremo cuyo objetivo era controlar el uso de las fuerzas de Carabineros. Este Decreto fue firmado por el Ministro del Interior, Andrés Chadwick, un día antes del homicidio de Camilo Catrillanca a manos de otro funcionario policial. Ver

https://www.interior.gob.cl/media/2018/10/PUBLICACION-ACUERDO.pdf

48 Walter Ramírez Inostroza fue condenado en 2010 por la Corte Marcial a tres años y un día, bajo libertad vigilada por el delito de violencias innecesarias con causa de muerte contra el estudiante Matías Catrileo.

B ANUARI DEL CONFLICTE SOCIAL 2018 
fuego. Se presentaron pruebas de indumentaria policial con impactos de bala como prueba. El examen forense arrojó que Jaime Mendoza Collío no había ocupado armas de fuego y que el disparo fue recibido por la espalda. Respecto a la indumentaria policial, se determinó que los disparos fueron realizados con posterioridad a la muerte del comunero. El año 2010 la Justicia Militar confirmó la tesis del montaje. Estos hechos ocurrieron mientras el Estado de Chile era examinado por el "Comité para la Eliminación de la Discriminación Racial de Naciones Unidas" 49 .

La realización de montajes como los referidos, con participación de las instituciones del Estado, el tratamiento de los hechos de manera distorsionada y como eventos únicos o excesos individuales, así como la atribución de responsabilidad a las víctimas de los eventos que las dañaron, son actuaciones del poder institucional que prolongan y profundizan el impacto de la violencia, a lo que se suma una justicia que llega inoportuna e insuficiente en la gran mayoría, si no en todos los $\operatorname{casos}^{50}$, lo que se traduce en una experiencia y percepción de discriminación racial frente a los órganos de justicia.

49 En el documento "Observaciones finales del Comité para la Eliminación de la Discriminación Racial Chile” (CERD/C/CHL/CO/15-18, 13 de agosto de 2009), en el apartado C. Motivos de preocupación y recomendaciones, punto $\mathrm{N}^{\circ} 19$, señala: "El Comité observa con preocupación las alegaciones sobre abusos y violencia ejercida por parte de los Carabineros contra miembros del pueblo mapuche, en el contexto de allanamiento y otras operaciones policiales. El Comité toma nota con consternación de la muerte del joven mapuche Jaime Facundo Mendoza Collío ocurrida el 12 de agosto de 2009, como consecuencia de disparos de Carabineros (Artículo 5(b)). El Comité recomienda que: a) el Estado parte investigue las quejas de abusos y violencia contra las personas pertenecientes a los pueblos indígenas cometidas por algunos miembros de las fuerzas armadas; b) que sean enjuiciadas y sancionadas las personas responsables de dichos actos y que una reparación sea otorgada a las víctimas o a los familiares de las víctimas. Asimismo, el Comité exhorta al Estado parte a que tome las medidas oportunas para prevenir dichos actos y, a este respecto, le recomienda que refuerce la capacitación en derechos humanos a las fuerzas armadas del Estado, incluyendo las disposiciones contenidas en la Convención."

50 El Comité contra la Tortura de Naciones Unidas, en sus Observaciones de agosto de 2018 al Examen de Chile, en el punto 26, relativo a la "Investigación, enjuiciamiento y sanción de actos de tortura y malos tratos", manifiesta su preocupación respecto a las bajas penas impuestas a los autores de estos delitos "en ningún caso las penas de prisión impuestas a los autores excedieron los tres años”. 
Las consecuencias de la criminalización contra el Pueblo Mapuche deben comprenderse como constitutivas de un trauma psicosocial, lo que conlleva un daño transgeneracional. Desde la perspectiva psicosocial, se entiende que el origen del trauma, sus consecuencias y manifestaciones se establecen "en las relaciones sociales y no exclusivamente en quien es víctima de esta experiencia. Esto evidencia que las experiencias traumáticas tienen impacto al interior de contextos socializadores, como la familia, la comunidad y las organizaciones sociales" (Martín Baró, 1988: 135; Faúndez, Brackelaire \& Cornejo, 2013: 4). Así, los niños y niñas quedan expuestos al dolor de las heridas de sus padres y familias, así como al impacto provocado por la violencia contra sus comunidades, además de ser víctimas de agresiones directas por parte de las policías ${ }^{51}$, generando la aparición de cuadros de estrés postraumático ${ }^{52}$ que se cronifica y reedita frente a cada nueva situación de violencia policial e institucional, apareciendo también sintomatología de la esfera depresiva y adaptativa.

Como subraya Martín Baró (1990), el trauma psicosocial encuentra sus raíces en la esfera social, pudiendo expresarse en formas de polarización social, violencia y mentira institucionalizada, las que se expresan también en la instalación de estereotipos estigmatizantes, que en este caso reducirían y deshumanizarían a los miembros del Pueblo Mapuche a partir de calificativos, la mayor parte de las veces, racistas. De esta manera, el Estado hace sentir de forma violenta y sistemática, en todos los ámbitos de existencia, la asimetría de poder. Y si bien las consecuencias físicas y psicológicas se manifiestan principalmente a nivel individual, es la sociedad en su conjunto la que resulta impactada, especialmente si se naturaliza la represión y la criminalización como

51 Dentro de las agresiones realizadas por efectivos policiales denunciadas se encuentran homicidios, secuestros, golpizas, desnudamientos, insultos racistas, amenazas de muerte, amenazas de dañar a un familiar cercano, amenazas con arma de fuego, persecución con vehículo policial, amenaza de atropellar a un menor de edad mientras corría delante del carro policial, disparos, presenciar muertes, detenciones violentas, golpizas, amenazas, humillaciones y malos tratos a seres queridos e interrogatorios ilegales, entre otras.

52 Debe considerarse que el primer criterio establecido para el diagnóstico de estrés postraumático es la exposición directa o indirecta a la muerte, lesión grave o violencia sexual. 
estrategias de control político para regular el orden social por medio de la provocación de miedo, dolor y amenaza.

\section{Algunas consideraciones finales}

El proceso de criminalización descrito en este capítulo no atañe solamente el ámbito jurídico, tiene efectos también en la vida cotidiana de numerosas personas mapuche y no-mapuche, pues al instaurar dicotomías ficticias, "zonas de no-derecho" y "estados de excepción" tiende a naturalizar las violencias policiales ejercidas hacia sus habitantes y, de forma más amplia, a invisibilizar o negar toda crítica a esta política del Estado. En tal contexto, la labor de defender imputados mapuche o litigar en contra de las diversas situaciones de violaciones de derechos se ha enfrentado a varias resistencias, en primer lugar, de parte de las instituciones y de los tribunales, pero también por parte de sectores políticos y económicos de la sociedad regional. Tales situaciones de transversalización de la criminalización han afectado incluso el trabajo de los abogados litigantes de estas causas, que han sido vigilados y hostigados por personal policial ${ }^{53}$ o se han visto afectados en su libre ejercicio de la profesión en proyectos académicos con las Cortes de Apelación destinados a mejorar el acceso a la justicia de la población mapuche ${ }^{54}$.

Dentro de este contexto de criminalización, la invocación de la Ley 18.314 sobre Conductas Terroristas en contra de personas mapuche implica reconocer de manera formal un estado de excepción en la región, en particular, en aquellas comunidades mapuche que reivindican sus derechos territoriales. Esta ley especial se ha sobre utilizado por parte de los gobiernos de turno y, además, el Ministerio Público, lo que evidencia una persecución en contra de las comunidades y organizaciones mapuche que actualmente se

${ }^{53}$ Un documento redactado por el equipo del Centro de Investigación y Defensa Sur - Cidsur (2018) detalla diversas situaciones de persecución a sus profesionales que han sido objeto de recursos y de denuncias.

${ }^{54}$ Informes alternativos para el tercer Ciclo del Examen Periódico Universal del Estado de Chile: principales afectaciones a los derechos humanos referidas a Naciones Originarias, personas migrantes, niñez y adolescencia, sexualidades y géneros, violencia institucional y derechos ambientales. Compiladores Centro de Derechos Humanos de la Universidad de Chile. Chile, 2018. Pág. 27. 
encuentran reivindicando sus derechos territoriales y políticos, lo que denominamos una utilización arbitraria y excesiva de esta ley. Así también lo han declarado los organismos internacionales ${ }^{55}$, pues le otorga ventajas procesales como, por ejemplo, lo relacionado con la prisión preventiva reforzada ${ }^{56}$ o la ampliación de la detención por diez días ${ }^{57}$.

La Ley sobre Conductas Terroristas consagra no solo un espacio jurídico donde las garantías judiciales de los imputados se ven seriamente afectadas en favor de una investigación con mayores facultades intrusivas, sino que también conlleva una descalificación de las pretensiones políticas de los comuneros mapuche que son investigados bajo esta normativa, así como de las comunidades a las que ellos pertenecen. Esto produce, entre otras consecuencias, la investigación de personas y organizaciones mapuche mediante la Ley de Inteligencia, situación que permitió la detención de autoridades y dirigentes mapuche en el caso Huracán a través de la inoculación de mensajes falsos en sus teléfonos celulares. Mientras que, a nivel comunitario, estas situaciones conllevan a la estigmatización de los dirigentes y autoridades tradicionales considerados como radicales, creando un clima de desconfianza y de temor de ser detenidos por relacionarse o comunicarse con ellos.

En este sentido, la Operación Huracán ha marcado un hito en la forma de ejercer la criminalización estatal en contra del Pueblo Mapuche, debido a que el fracaso de este caso fue de tal magnitud, que afectó la credibilidad de la institucionalidad jurisdiccional completa, es decir, a los Tribunales de Justicia, incluyendo al Ministerio Público, como persecutor de delitos, y a Carabineros como auxiliar de este

55 Los expertos de la ONU, Victoria Tauli-Corpuz, Relatora Especial sobre los derechos de los pueblos indígenas; José Antonio Guevara Bermúdez, Presidente Relator del Grupo de Trabajo sobre la Detención Arbitraria y Fionnuala Ní Aoláin, Relatora Especial sobre la promoción y la protección de los derechos humanos y las libertades fundamentales en la lucha contra el terrorismo el 6 de Octubre del 2017 solicitaron a través de un Informe al Estado Chileno no utilizar la ley que califica conductas terroristas.

56 Para lograr el cambio de medida cautelar de prisión preventiva, se necesita la unanimidad de los miembros de la Corte de Apelaciones según lo establecido en la Constitución Política de la República respecto a los delitos terroristas.

${ }^{57}$ En las investigaciones por ley común las detenciones solo pueden ampliarse hasta por tres días. 
último, demostrando el descontrol del sistema de inteligencia en Chile. Así entonces, pareciera que, luego de ello, la política criminal ha mutado desde una labor de "investigación eficaz" hacia una estrategia de "prevención del delito", instaurando un comando de funcionarios policiales capaz de operar en tiempos de paz con armamento de guerra. En pocas palabras, Carabineros de Chile en menos de un año ha variado su estrategia operacional desde las labores de "inteligencia" a la de "fuerza bruta", demostrando en ambos casos lo peligroso que es otorgar facultades excesivas a la policía ya sea en el ámbito de la información o en el uso de la fuerza.

El denominador común en ambas estrategias es la invocación, por parte del Ministerio Público y del Poder Ejecutivo, de la Ley de Conductas Terroristas, criminalizando y estigmatizando a los involucrados, todos reconocidos líderes y autoridades tradicionales con un papel relevante en la resistencia y desarrollo de la lucha reivindicativa mapuche. Por lo anterior, es posible afirmar que la insistencia estatal en calificar como terrorismo aquellos delitos en los que son imputados miembros y líderes del Pueblo Mapuche, recae en la posibilidad de justificar los fuertes niveles de represión y militarización en los territorios y comunidades, aumentando al mismo tiempo la polarización social y su aislamiento.

Además de lo expuesto, es necesario señalar que la estrategia de criminalización ha permitido mantener la atención principalmente en las actuaciones del Estado respecto al Pueblo Mapuche, soslayando la importancia política de otros actores sociales como los sectores gremiales y los actuales ocupantes de las tierras reivindicadas. Como señala Daniel Feierstein, estos últimos grupos tienden a presentarse como "víctimas neutrales", generando una suerte de "Teoría de los Dos Demonios" 58, señalando que "el procedimiento político fundamental es este escamoteo del conflicto a partir de construir una "neutralidad" social: la de la "gente común" victimizada por los "demonios" (2018:12). Debe considerarse, por ejemplo, que la presencia de la policía militarizada, además de reprimir a las comunidades, cumple medidas cautelares de protección de la

\begin{abstract}
58 Si bien no existe una definición establecida, la Teoría de los Dos Demonios remite a una referencia abstracta a la "violencia" como una figura unívoca que tiende a homologar las diversas acciones de subversión y resistencia armada con los secuestros, desapariciones o asesinatos cometidos por agentes del Estado.
\end{abstract}


propiedad privada de grandes empresas y agricultores, aumentando la sensación de desigualdad.

Estas distintas situaciones explican por qué a pesar de la existencia de procesos judiciales y algunas condenas, se mantiene un sentimiento de injusticia e impunidad tanto en las comunidades como en gran parte de la población mapuche que vive en la ciudad. En este sentido, las políticas de criminalización y la impunidad que le acompaña, se presentan como un importante vector y cimiento de la identidad colectiva de un pueblo en busca de justicia. Una autoridad tradicional mapuche, explica esta realidad con gran claridad.

“...y acá de repente igual uno, si uno ha alzado la voz es por la libertad que antiguamente los mapuche tuvieron, los mapuche fueron libres, caminaban en hacer sus cosas, todo, y en la cual ahora no nos veímos y tenemos gente, jóvenes, involucrados y perseguidos, que han estado en la clandestinidad, y ahora último un peñi (hermano) asesinado en la comunidad, pu. Eso, toda esa...tema, por ejemplo, nosotros nos hemos venido planteando, con anticipación, por ejemplo, de que diciendo...en distintas manifestaciones y haciendo comunicados, repudiando algunas cosas que...para evitar que esto suceda. Pero aquí hay una persecución...política dentro del Pueblo Mapuche, y muy en especial nuestra comunidad, hemos ido pasando toda esta cuestión, pu. Y ahora ya pasó al extremo donde no hace más...ni medio año que se instaló el Comando Jungla y asesinaron a un peñi en la comunidad. Y esto, mientras no haya un cambio respecto de estos temas esto va...va a seguir, va a seguir sucediendo, porque al final nosotros, esta lucha la damos por una convicción, no por una necesidad. Por un derecho que el mapuche en algún momento se le arrebató por las...bajo las armas, y nos hemos visto así...y este, por ejemplo, ahora, cuando cayó el peñi, fue una pena, después una rabia, esa rabia después se transforma en una convicción de lucha... Porque al final ellos [los responsables del homicidio de Camilo Catrillanca] nunca, en ningún momento, ni un rato van a estar en la cárcel...entonces eso es preocupante, indignante, para mí, pu, para mí y también para los jóvenes, para los lamgenes (hermanas) que van, por ejemplo, tomando conciencia de la lucha o identificándose 
quienes son, porque hay hartos mapuche, no todos los mapuche piensan eso. Si un mapuche piensa de eso, ya pasa a ser como un enemigo del Estado, y entonces ahí viene la persecución, y que no lo dejen tranquilo" 59 .

El giro observado en el caso de la Operación Huracán y el fallido intento de encubrimiento del asesinato de Camilo Catrillanca se enmarca en una crisis mayor de la institucionalidad tanto policial como judicial (Duce, 2019), donde estos montajes aparecen como el revelador o el gatillo de otros escándalos que atañen principalmente a Carabineros y el Ministerio Público, pero que involucran también a políticos y magistrados. De tal forma, la coyuntura del Pueblo Mapuche se ha vuelto el centro de las preocupaciones democráticas en Chile y, por lo tanto, se erige en un actor imprescindible en los futuros cambios que se espera que experimente el país en esta materia.

\section{Bibliografía}

Artinian, J. P. (2019) "El problema de la negación como última etapa de los genocidios" Universidad de Buenos Aires, CABA. 05 de agosto de 2019.

Barudy, J. y Marquebreuq A. (2006). Hijas e hijos de madres resilientes. Traumas infantiles en situaciones extremas: violencia de género, guerra, genocidio, persecución y exilio. Editorial Gedisa, España.

Boccara, G. (2012). «La interculturalidad como campo social». Cuadernos Interculturales 10(18):11-30.

Bresciani, C., Fuenzalida, J., Rojas, N. \& Soto, D. (2019). Mitos chilenos sobre el Pueblo Mapuche. Santiago: Ediciones Universidad Alberto Hurtado: Primera Edición. 177 pp.

Casanueva, F. (1998). "Indios malos en tierras buenas: visión y concepción del mapuche según las elites chilenas del siglo XIX». Pp. 55-131 en Modernización, Inmigración y Mundo Indigena:

59 Entrevista a autoridad tradicional mapuche de comunidad que sufre militarización, Provincia de Malleco, noviembre de 2018. 
Chile y la Araucanía en el siglo XIX, editado por J. Pinto. Temuco: Universidad de La Frontera.)

Centro de Investigación y Defensa Sur - Cidsur. (2018). s/n, Temuco. Colectivo Editorial Mapuexpress (2016). Resistencias Mapuche al extractivismo, Santiago: Editorial Quimantú.

Consejo Nacional de Infancia (2015). Comisión Técnica de Niñery Pueblos Indigenas. Santiago, Chile: Ministerio Secretaría General de la Presidencia. 111 páginas. En https://biblioteca.digital.gob.cl/bitstream/handle/123456789/ 210/Comision $\% 20$ tecnica $\% 20 \mathrm{de} \% 20$ ninez $\% 20$ indigena.pdf?se quence $=1$ \&is Allowed $=\mathrm{y}$

Comité de los Derechos del Niño. (2015). Observaciones finales sobre los informes periódicos cuarto y quinto combinados de Chile. p.19 Disponible en

https://otdchile.org/wp-content/uploads/2018/08/Observaciones-

finales-sobre-los-informes-perio $\% \mathrm{CC} \% 81$ dicos-cuarto-y-

quinto-combinados-Comite $\%$ CC $\% 81$-de-los-Derechos-del-

Nin\%CC\%83o.pdf

Correa, M. y Mella Seguel, E. (2010). Las razones del illkun/enojo: memoria despojo y criminalización en el territorio mapuche de Malleco. 1. ed. Santiago: LOM: Observatorio de Derechos de los Pueblos Indígenas.

Couso, J. (2013). "Mapuches y Derecho Penal" In: Olea Rodríguez, Helena (ed.) Derecho y Pueblo Mapuche: aportes para la discusión. Santiago: Centro de Derechos Humanos UDP, pp. 155 -214.

Duce, M. (2019). "CARABINEROS: LA HORA DE UNA REFORMA PROFUNDA", Revista Mensaje, enero-febrero 2019, n676, VOL. LXVIII. pp. 8-10.

Faúndez, X., Brackelaire, J. \& Cornejo, M. (2013). Transgeneracionalidad del Trauma Psicosocial: Imágenes de la Detención de Presos Políticos de la Dictadura Militar Chilena Reconstruidas por los Nietos. Psykhe (Santiago), 22(2), 83-95. https://dx.doi.org/10.7764/psykhe.22.2.563

Feierstein, D. (2018). Los dos demonios (recargados). $1^{\circ}$ ed. Ciudad Autónoma de Buenos Aires: Marea. 240 p.

Fernández Droguett, F. y Ojeda Cisternas, D. (2015). «Criminalization of Mapuche resistance and politics of fear». Athenea Digital. Revista de pensamiento e investigación social 15(4):267. 
Fundación Anide. (2011). Informe sobre violencia institucional hacia la niñez mapuche en Chile.Resumen Ejecutivo. Santiago, Chile. 67 páginas. En https://www.indh.cl/informe-sobre-violenciainstitucional-hacia-la-ninez-mapuche-en-chile/

Gandulfo, E. (1999). "Principio del derecho procesal penal en el el sistema de procedimiento chileno" Revista de Derecho de la Universidad Católica de Valparaíso: 1999. XX.

González, K. (2017). «"Liberar, liberar al mapuche por luchar!”. Activismo, derechos humanos y prisión política mapuche en Chile*». e-cadernos CES (28).

Hale, C. y Millaman, R. (2005). «Cultural Agency and Political Struggle in the Era of the Indio Permitido». Pp. 281-304 en Cultural Agency in the Americas, editado por D. Sommer. Durham: Duke University Press.

Jiménez Bustos, R., Perez-Luco Arenas, R., \& Bustamante Rivera, G. (2017). Identidad étnica y conductas sociales en adolescentes indígenas Mapuche sancionados por la Ley de Responsabilidad Penal Adolescente en regiones del sur de Chile. Universitas Psychologica, 16(1). https://doi.org/10.11144/Javeriana.upsy16$\underline{1 . i e c s}$

Le Bonniec, F. (2014). «Las Cárceles De La Etnicidad: Experiencias Y Prácticas De Resistencia De Los Mapuche Sometidos a La Violencia Política En La Era Del Multiculturalismo (20002010)». Oñati Socio-Legal Series 4(1).

Le Bonniec, F. (2014b). «Reconfiguration des figures paysagères et transformations environnementales en pays mapuche (XIXeXXIe siècles): Des forêts vierges et impénétrables aux vastes exploitations de bois exotiques». Caravelle (102):165-85.

Lepe-Carrion, P. (2018). «El discurso intercultural como campo de disputa: 'terrorismo mapuche' y dispositivo pedagógico de etnicidad ». Historia y Justicia (11):315-47.

Martín Baró, I. (1988). La violencia política y la guerra como causas del trauma psicosocial en El Salvador. Revista de Psicología de El Salvador, Vol.'28, pp 123-141 UCA, San Salvador. El Salvador, CA.

Martín Baró, I. (1990). Psicología Social de la Guerra: Trauma y Terapia. Selección e Introducción de Ignacio Martín-Baró. San Salvador, El Salvador: UCA Editores. 
Marx Ferree, M. (2005). "Soft Repression: Ridicule, Stigma and Silencing in Gender-based Movements » in Repression and Mobilization. Christian Davenport, Hank Johnston and Carol Mueller (eds). University of Minnesota Press. pp 138-155

Mella Seguel, E. (2014). «La Aplicación del Derecho Penal Común y Antiterrorista como Respuesta a la Protesta Social de Indígenas Mapuche Durante el Periodo 2000-2010 (The Implementation of Ordinary and Anti Terror Criminal Law in Response to the Social Protest by the Indigenous Mapuche People from 2000 to 2010)». Oñati Socio-Legal Series 4(1).

Molina González, C. (2010). "Informe sobre situaciones de violencia ejercida por el Estado de Chile contra niños y niñas Mapuche". Denuncia presentada en $53^{\circ}$ Período de sesiones Comité de los Derechos del Niño de Naciones Unidas, Ginebra 11 al 29 de enero de 2010. Temuco, Chile: Defensor Jurídico Social Autónomo Mapuche.

http://defensormapuche.blogspot.com/2010/02/estado-de-chilecontra-ninos-ninas-y.html

Molina González, C. (2014). "Violencia ejercida por el Estado de Chile contra niños y niñas mapuche". pp 127-140 en Rakizuam Tañi Wajmapu. El libro de Mapuexpress por la libredeterminación de los Pueblos. Santiago de Chile: Editorial Quimantú.

Pairicán, F. Malon. La rebelión del movimiento mapuche 1990-2013. Pehuén Editores: 2014. 418 pp.

Red de ONGs Infancia y Juventud Chile. (2014). Informe al Comité de los Derechos del Niño de las Naciones Unidas sobre la aplicación de las Convención de los Derechos del Niño en Chile. Presentado al Comité de los Derechos de la Niñez, Ginebra Suiza. Santiago, Chile: ROIJ. 44 páginas. En

https://tbinternet.ohchr.org/Treaties/CRC/Shared\%20Documents/ CHL/INT CRC NGO CHL 19437 S.pdf

Rojas Pedemonte, N. y Miranda, O. (2017). «Dinámica sociopolítica del conflicto y la violencia en territorio mapuche. Particularidades históricas de un nuevo ciclo en las relaciones contenciosas». Revista de Sociología 0(30).

Villegas, M. (2009). "El mapuche como enemigo en el derecho penal: consideraciones desde la biopolítica y el derecho penal del enemigo". Portal iberoamericano de las ciencias penales. 
Villegas, M. (2018). "Tratamiento jurisprudencial del terrorismo en Chile (1984-2016)".Polit. crim. Vol. 13, No 25 (Julio 2018) Art. 13, pp. 501-547. Disponible en:

[http://www.politicacriminal.cl/Vol 13/n 25/Vol13N25A13.pdf]. Vera Lama, R. (2017). Sistema de Inteligencia Cbileno. Santiago: Editorial Metropolitana.

\section{Cronología 2018}

\begin{tabular}{|l|l|l|}
\hline Fecha & Acontecimiento & Descripción \\
\hline $\begin{array}{l}\text { enero de de } \\
2018\end{array}$ & $\begin{array}{l}\text { El Mercurio revela } \\
\text { "Ministerio Público investiga } \\
\text { filtración de información a } \\
\begin{array}{l}\text { Héctor Llaitul desde la } \\
\text { fiscalía y la ANI" }\end{array}\end{array}$ & $\begin{array}{l}\text { Esta noticia será el gatillo que va a generar un debate } \\
\text { público sobre las inconsistencias de las informaciones } \\
\text { entregadas por servicios de inteligencia en el caso } \\
\text { "Operación Huracán", las cuales habían derivado en la } \\
\text { detención y formalización de ocho autoridades, dirigentes y } \\
\text { activistas mapuche en septiembre de 2017. }\end{array}$ \\
\hline $\begin{array}{l}\text { enero de de } 2018 \\
\text { enuncia la decisión de no } \\
\text { perseverar en la } \\
\text { investigación por asociación } \\
\text { ilícita terrorista que afectaba } \\
\text { a ocho personas mapuches } \\
\text { en el marco de la } \\
\text { denominada "Operación } \\
\text { Huracán" }\end{array}$ & $\begin{array}{l}\text { El Manisterio Público en el Juzgado de Garantía de Temuco, } \\
\text { indica que las informaciones que entregó la UIOE } \\
\text { adolecen de serias irregularidades", "están manipuladas" y } \\
\text { parte de terceros", refiriéndose a los mensajes de whatsapp } \\
\text { supuestamente encontrados en los teléfonos de algunos de } \\
\text { los imputados. }\end{array}$ \\
\hline $\begin{array}{l}\text { 09 de } \\
\text { febrero } \\
\text { de 2018 }\end{array}$ & $\begin{array}{l}\text { Audiencia de discusión de } \\
\text { sobreseimiento de los delitos } \\
\text { de asociación ilícita e } \\
\text { incendio Terrorista en el } \\
\text { caso derivado de la } \\
\text { denominada "Operación } \\
\text { Huracán" }\end{array}$ & $\begin{array}{l}\text { El Sr. Juez de Garantía, don Federico Gutiérrez Salazar } \\
\text { resolvió acoger la solicitud de las defensas, decretando el } \\
\text { sobreseimiento definitivo en atención al artículo 250 letra b) } \\
\text { del Código Procesal Penal, esto es por aparecer claramente } \\
\text { establecida la inocencia de los imputados en los delitos que } \\
\text { se le habían imputado. }\end{array}$ \\
\hline
\end{tabular}




\begin{tabular}{|c|c|c|}
\hline $\begin{array}{l}12 \text { de } \\
\text { febrero } \\
\text { de } 2018\end{array}$ & $\begin{array}{l}\text { Presentación de querella de } \\
\text { los dirigentes mapuche } \\
\text { afectados por la "Operación } \\
\text { Huracán" }\end{array}$ & $\begin{array}{l}\text { Se presenta querella en contra de los miembros de } \\
\text { Carabineros de Chile involucrados en el montaje } \\
\text { denominado "Operación Huracán", y en contra todos } \\
\text { quienes resulten responsables por los hechos. } \\
\text { La acción es presentada por los hermanos, Jaime y Rodrigo } \\
\text { Huenchullan Cayul de la comunidad Autónoma de } \\
\text { Temucuicui y por el machi Fidel Tranamil Nahuel de Rofue. }\end{array}$ \\
\hline $\begin{array}{l}27 \text { de } \\
\text { febrero } \\
\text { de } 2018\end{array}$ & $\begin{array}{l}\text { Corte de Apelaciones de } \\
\text { Temuco revoca } \\
\text { sobreseimiento definitivo de } \\
\text { los ocho mapuche afectados } \\
\text { por la "Operación Huracán" }\end{array}$ & $\begin{array}{l}\text { En base a las apelaciones deducidas por el Ministerio } \\
\text { Público y la Intendencia Regional de la Araucanía, en su } \\
\text { calidad de querellante, la Corte de Apelaciones de Temuco, } \\
\text { revoca la resolución dictada por el Juzgado de Garantía de } \\
\text { Temuco, dejando sin efecto el sobreseimiento definitivo } \\
\text { decretado respecto de los ocho imputados de la Operación } \\
\text { Huracán, teniendo presente la comunicación de no } \\
\text { perseverar efectuada por el Ministerio Público. }\end{array}$ \\
\hline $\begin{array}{l}11 \text { de } \\
\text { junio de } \\
2018\end{array}$ & $\begin{array}{l}\text { Tribunal de Juicio Oral en lo } \\
\text { Penal de Temuco dicta } \\
\text { sentencia condenatoria en } \\
\text { caso Luchsinger Mackay }\end{array}$ & $\begin{array}{l}\text { El Tribunal de Juicio Oral en lo Penal de Temuco, } \\
\text { compuesto por los jueces Germán Varas Cicarelli, Rocío } \\
\text { Pinilla Dabbadie y José Mauricio Poblete Erices, dicta } \\
\text { sentencia condenatoria respecto de Luis Tralcal Quidel, José } \\
\text { Tralcal Coche y José Peralino Huinca, por el delito de } \\
\text { incendio con resultado de muerte de carácter terrorista, } \\
\text { condenando a los primos Tralcal a cumplir la pena de } \\
\text { presidio perpetuo simple y a Peralino Huinca la pena de } 5 \\
\text { años de presidio menor en su grado máximo. }\end{array}$ \\
\hline $\begin{array}{l}13 \text { de } \\
\text { junio de } \\
2018\end{array}$ & $\begin{array}{l}\text { Audiencia para discusión de } \\
\text { sobreseimiento definitivo, en } \\
\text { virtud de nuevos } \\
\text { antecedentes en el caso } \\
\text { derivado de la denominada } \\
\text { "Operación Huracán }\end{array}$ & $\begin{array}{l}\text { Las defensas solicitan audiencia para discutir nuevamente el } \\
\text { sobreseimiento definitivo en atención a antecedentes que } \\
\text { surgieron en la investigación paralela que llevaba la fiscalía } \\
\text { contra ex miembros de la UIOE Araucanía, cuyos } \\
\text { imputados son el General (r) Gonzalo Blu Rodríguez, el } \\
\text { Mayor (r) Patricio Marín Lazo, el Capitán (r) Leonardo } \\
\text { Osses, y Alex Smith Leay (CPR de Carabineros durante el } \\
\text { 2017), entre otros. En dicha investigación surgieron } \\
\text { antecedentes que demostraban fehacientemente la falsedad } \\
\text { de las supuestas aplicaciones que lograban interceptar } \\
\text { aplicaciones de mensajería instantánea, por lo que se } \\
\text { comprobó que los antecedentes que se tuvieron en cuenta } \\
\text { para ordenar la detención y posteriormente la formalización } \\
\text { y prisión preventiva de los ocho imputados mapuche eran } \\
\text { falsos. } \\
\text { En esta audiencia se decretó el sobreseimiento definitivo } \\
\text { por el delito de asociación ilícita terrorista en favor de todos } \\
\text { los imputados, y respecto del delito de incendio terrorista se } \\
\text { denegó la solicitud de decretar el sobreseimiento definitivo, } \\
\text { por lo que se sigue teniendo presente la decisión de no } \\
\text { perseverar. Además, se condenó al pago de costas }\end{array}$ \\
\hline
\end{tabular}




\begin{tabular}{|l|l|l|}
\hline & únicamente a la Intendencia Regional de la Araucanía, \\
eximiéndose al Ministerio Público.
\end{tabular}




\begin{tabular}{|c|c|c|}
\hline & & $\begin{array}{l}\text { la pena aplicable. Así, Luis Tralcal Quidel y José Tralcal } \\
\text { Coche fueron condenados a } 18 \text { años de presidio mayor en } \\
\text { su grado máximo por el delito de incendio común con } \\
\text { resultado de muerte y mantuvo la pena de } 5 \text { años de presidio } \\
\text { menor en su grado máximo para José Peralino Huinca, por } \\
\text { el mismo delito. }\end{array}$ \\
\hline $\begin{array}{l}30 \text { de } \\
\text { octubre } \\
\text { de } 2018\end{array}$ & $\begin{array}{l}\text { Formalización del Mayor }(\mathrm{R}) \\
\text { Patricio Marín Lazo por su } \\
\text { responsabilidad en el } \\
\text { Montaje derivado de La } \\
\text { "Operación Huracán" }\end{array}$ & $\begin{array}{l}\text { Se logra formalizar al Mayor (R) de Carabineros Patricio } \\
\text { Marín Lazo, quien había sido citado en conjunto con los } \\
\text { demás imputados ya formalizados el día } 09 \text { de julio de 2018, } \\
\text { pero a través de distintas estrategias dilatorias había logrado } \\
\text { aplazar su formalización. Se le aplica igual que a los oficiales } \\
\text { ya formalizados. la medida cautelar de Prisión Preventiva } \\
\text { por los mismos delitos ya señalados. }\end{array}$ \\
\hline $\begin{array}{l}14 \text { de } \\
\text { noviem } \\
\text { bre, } \\
2018\end{array}$ & $\begin{array}{l}\text { Homicidio de Camilo } \\
\text { Catrillanca y homicidio } \\
\text { frustrado del adolescente de } \\
\text { iniciales M.A.P.C. }\end{array}$ & $\begin{array}{l}\text { El joven mapuche Camilo Catrillanca es asesinado por } \\
\text { Carlos Alarcon Molina, miembro del llamado "Comando } \\
\text { Jungla" en la comunidad de Temucuicui, Ercilla. } \\
\text { Conjuntamente, otro de los integrantes del Comando } \\
\text { Jungla, Raúl Ávila Morales procede a detener y golpear al } \\
\text { adolescente M.A.P.C., quien acompañaba a Camilo } \\
\text { Catrillanca en el tractor que los trasladaba. } \\
\text { La primera versión de Carabineros, daba cuenta de que los } \\
\text { funcionarios del GOPE habían sido víctimas de disparos } \\
\text { por desconocidos, que en consecuencia debieron efectuar } \\
\text { disparos disuasivos y que el tractor conducido por Camilo } \\
\text { Catrillanca se cruzó en la línea de fuego. }\end{array}$ \\
\hline $\begin{array}{l}15 \text { de } \\
\text { noviem } \\
\text { bre, } \\
2018\end{array}$ & $\begin{array}{l}\text { Formalización del } \\
\text { adolescente M.A.P.C. }\end{array}$ & $\begin{array}{l}\text { El adolescente mapuche M.A.P.C. es formalizado en el } \\
\text { Juzgado de Garantía de Collipulli por el delito de } \\
\text { receptación de vehículos. La detención fue declarada ilegal, } \\
\text { ya que la misma se basaba en la declaración conjunta } \\
\text { presentada por los mismos funcionarios del Comando } \\
\text { Jungla, la cual daba cuenta de antecedentes falsos relativos a } \\
\text { la dinámica de los hechos. }\end{array}$ \\
\hline $\begin{array}{l}16 \mathrm{de} \\
\text { noviem } \\
\text { bre, } \\
2018\end{array}$ & $\begin{array}{l}\text { Viaje del General Director } \\
\text { de Carabineros a La } \\
\text { Araucanía. }\end{array}$ & $\begin{array}{l}\text { Hermes Soto Isla, a la sazón Director General de } \\
\text { Carabineros, arriba a la capital Regional, donde sostiene } \\
\text { diversas reuniones con sus subalternos, incluyendo los } \\
\text { miembros del Comando Jungla. La información recopilada } \\
\text { mantiene la versión mendaz sostenida por la policía militar, } \\
\text { en cuanto el tractor se habría cruzado en la línea de fuego y } \\
\text { que no existía registro videográficos del procedimiento. }\end{array}$ \\
\hline
\end{tabular}




\begin{tabular}{|c|c|c|}
\hline $\begin{array}{l}17 \text { de } \\
\text { noviem } \\
\text { bre de } \\
2018\end{array}$ & $\begin{array}{l}\text { Se revela que miembros del } \\
\text { Comando Jungla utilizaron } \\
\text { cámaras GO Pro durante el } \\
\text { procedimiento policial }\end{array}$ & $\begin{array}{l}\text { Producto de la investigación fue posible visualizar los } \\
\text { registros de videos grabados por funcionarios de Fuerzas } \\
\text { Especiales (FFEE) de Carabineros, donde - además de } \\
\text { descartarse el supuesto enfrentamiento - era visible la } \\
\text { utilización de cámaras por parte Raúl Ávila, miembro del } \\
\text { Comando Jungla. } \\
\text { Entrevistado acerca de tales imágenes, el funcionario } \\
\text { reconoció la existencia de grabaciones, indicando que, sin } \\
\text { embargo, habían sido destruidas por contener imágenes } \\
\text { íntimas con su esposa. }\end{array}$ \\
\hline $\begin{array}{l}20 \text { de } \\
\text { noviem } \\
\text { bre de } \\
2018\end{array}$ & $\begin{array}{l}\text { Luis Mayol Bouchon } \\
\text { presenta su renuncia al cargo } \\
\text { como Intendente de la } \\
\text { Región de la Araucanía }\end{array}$ & $\begin{array}{l}\text { La renuncia es presentada en medio de los cuestionamientos } \\
\text { y amenazas de acusación constitucional en contra del } \\
\text { Intendente Mayol por declaraciones efectuadas durante las } \\
\text { horas posteriores a la muerte de Camilo Catrillanca. } \\
\text { En efecto, la autoridad regional había afirmado la } \\
\text { participación de la víctima en el robo de los vehículos que } \\
\text { dio inicio al procedimiento policial, indicando además que } \\
\text { este contaba con antecedentes penales previos por } \\
\text { receptación, situación que fue desmentida posteriormente } \\
\text { por la propia investigación y por la publicación del extracto } \\
\text { de filiación de Catrillanca, con el cual se comprobaba que la } \\
\text { víctima no tenía antecedentes penales. }\end{array}$ \\
\hline $\begin{array}{l}27 \text { de } \\
\text { noviem } \\
\text { bre de } \\
2018\end{array}$ & $\begin{array}{l}\text { Se suspende entrenamiento } \\
\text { del "Comando Jungla" }\end{array}$ & $\begin{array}{l}\text { El entonces General Director de Carabineros, Hermes Soto, } \\
\text { anuncia la suspensión del entrenamiento y preparación de } \\
\text { funcionarios del GOPE en Colombia y que evaluarán su } \\
\text { continuidad con el Gobierno. }\end{array}$ \\
\hline $\begin{array}{l}30 \text { de } \\
\text { noviem } \\
\text { bre, } \\
2018\end{array}$ & $\begin{array}{l}\text { Formalización de cargos } \\
\text { contra los miembros del } \\
\text { Comando Jungla que } \\
\text { participaron en la muerte de } \\
\text { Camilo Catrillanca }\end{array}$ & $\begin{array}{l}\text { Ante el Juzgado de Garantía de Collipulli se formaliza a } \\
\text { Carlos Alarcón Molina y Raúl Ávila Morales como autores } \\
\text { de homicidio de Camilo Catrillanca y Homicidio frustrado } \\
\text { de M.A.P.C. Ávila Morales también fue formalizado por } \\
\text { infidelidad en custodia de documentos por la destrucción de } \\
\text { la tarjeta de memoria de los videos. } \\
\text { Asimismo, son formalizados los miembros del comando } \\
\text { Jungla que los acompañaban, Patricio Sepúlveda Muñoz y } \\
\text { Braulio Valenzuela Aranguiz como autores de obstrucción a } \\
\text { la investigación. }\end{array}$ \\
\hline
\end{tabular}




\begin{tabular}{|c|c|c|}
\hline $\begin{array}{l}2 \text { de } \\
\text { diciemb } \\
\text { re de } \\
2018\end{array}$ & $\begin{array}{l}\text { Se viraliza video con } \\
\text { declaraciones de Carlos } \\
\text { Alarcón Molina, imputado } \\
\text { por el homicidio de Camilo } \\
\text { Catrillanca. }\end{array}$ & $\begin{array}{l}\text { Por redes sociales se da a conocer un video grabado en por } \\
\text { Carlos Alarcón Molina en dependencias del recinto policial } \\
\text { en el cual se encontraba cumpliendo la cautelar de prisión } \\
\text { preventiva. En dicho video expresaba sus agradecimientos a } \\
\text { quienes habían apoyado a Carabineros frente a las } \\
\text { imputaciones por el homicidio de C. Catrillanca Marín y el } \\
\text { homicidio frustrado de M.A.P.C. En dicho contexto, señala } \\
\text { "todavía falta que salgan cosas a la luz" "aquí hay gente que } \\
\text { nos hizo mentir, dimos declaraciones falsas y ahora nosotros } \\
\text { somos los más malos, los más peligrosos para la } \\
\text { ciudadanía". } \\
\text { Dichas declaraciones dieron lugar a que se abriera una nueva } \\
\text { arista en la indagatoria, terminando con la imputación a altos } \\
\text { mandos de Carabineros por los delitos de obstrucción a la } \\
\text { investigación y falsificación de instrumento público, entre } \\
\text { otros. }\end{array}$ \\
\hline $\begin{array}{l}04 \text { de } \\
\text { diciemb } \\
\text { re de } \\
2018\end{array}$ & $\begin{array}{l}\text { Corte de Apelaciones de } \\
\text { Temuco acoge amparado } \\
\text { deducido por el INDH en } \\
\text { favor de familiares de } \\
\text { Camilo Catrillanca y } \\
\text { M.A.P.C }\end{array}$ & $\begin{array}{l}\text { La acción constitucional fue acogida por el máximo tribunal } \\
\text { regional, indicándose en ella que "Esta Corte constata que } \\
\text { efectivamente existe un temor válido en los recurrentes en cuantos } \\
\text { familiares de don Camilo Catrillanca Marín, de verse enfrentados } \\
\text { situaciones que configuren vulneración de sus derechos, razón por la } \\
\text { cual se acogerá el presente recurso solo en cuanto se solicita se ordene a } \\
\text { Carabineros de la IX Zona efectuar sus procedimientos con estricta } \\
\text { sujeción a la normativa constitucional y legal vigente, absteniéndose, en } \\
\text { lo sucesivo, de afectar los derechos fundamentales de las personas } \\
\text { amparadas, especialmente de aquellas que son niños, niñas y/o } \\
\text { adolescentes" }\end{array}$ \\
\hline $\begin{array}{l}08 \text { de } \\
\text { diciemb } \\
\text { re de } \\
2018\end{array}$ & $\begin{array}{l}\text { Presidente Sebastián Piñera } \\
\text { anuncia el retiro del } \\
\text { Comando Jungla de la } \\
\text { Araucanía }\end{array}$ & $\begin{array}{l}\text { Producto de los cuestionamientos y movilizaciones iniciadas } \\
\text { a nivel nacional a raíz del asesinato de Camilo Catrillanca, } \\
\text { Piñera anuncia el retiro de la Araucanía del GOPE y el } \\
\text { Comando Jungla, indicando que en su lugar reforzarán el } \\
\text { equipo de Fuerzas Especiales. }\end{array}$ \\
\hline $\begin{array}{l}11 \text { de } \\
\text { diciemb } \\
\text { re de } \\
2018\end{array}$ & $\begin{array}{l}\text { Interpelación al Ministro del } \\
\text { Interior Andrés Chadwick. }\end{array}$ & $\begin{array}{l}\text { La diputada williche Emilia Nuyado encabeza la } \\
\text { interpelación del Ministro del Interior Andrés Chadwick, } \\
\text { quien había sido convocado por Congreso para explicar los } \\
\text { antecedentes y el actuar policial en torno al asesinato de } \\
\text { Camilo Catrillanca. } \\
\text { Además, antes de iniciar la sesión, el Congreso aprueba la } \\
\text { creación de una Comisión Investigadora por la muerte de } \\
\text { Camilo Catrillanca. }\end{array}$ \\
\hline
\end{tabular}




\begin{tabular}{|l|l|l|}
\hline $\begin{array}{l}19 \text { de } \\
\text { diciemb } \\
\text { re de } \\
2018\end{array}$ & $\begin{array}{l}\text { Se dan a conocer nuevos } \\
\text { videos del operativo policial } \\
\text { que terminó con el } \\
\text { homicidio de Camilo } \\
\text { Catrillanca. }\end{array}$ & $\begin{array}{l}\text { Los videos fueron captados por una cámara personal que en } \\
\text { el momento de los hechos llevaba el Suboficial Patricio } \\
\text { Sepúlveda, jefe de la patrulla del GOPE que encabezó el } \\
\text { procedimiento. Las imágenes, cuya existencia era } \\
\text { desconocida y negada hasta esa fecha, daban cuenta del } \\
\text { desplazamiento del tractor y de los 12 disparos efectuados } \\
\text { por los funcionarios policiales. Asimismo, mostraba la } \\
\text { forma violenta y desproporcionada en que el adolescente } \\
\text { M.A.P.C había sido reducido. } \\
\text { La entrega de estos videos por parte de la defensa de } \\
\text { Sepúlveda, descartaba las declaraciones oficiales de } \\
\text { Carabineros en torno a que la única grabación del } \\
\text { procedimiento (la que había realizado Raúl Ávila) había sido } \\
\text { destruida. }\end{array}$ \\
\hline $\begin{array}{l}\text { 20 de } \\
\text { diciemb } \\
\text { re de } \\
2018\end{array}$ & $\begin{array}{l}\text { Presidente Sebastián Piñera } \\
\text { solicita la renuncia del } \\
\text { General Director de } \\
\text { Carabineros Hermes Soto. }\end{array}$ & $\begin{array}{l}\text { Luego de que se diera a conocer la existencia de nuevos } \\
\text { videos del operativo policial del 14 de noviembre, el } \\
\text { Gobierno decide pedir la renuncia de Hermes Soto, } \\
\text { indicando que Carabineros necesitaba de un nuevo } \\
\text { liderazgo. A pesar de que durante las primeras horas Soto se } \\
\text { negó a renunciar, al día siguiente manifestó que aceptaba la } \\
\text { solicitud de la presidencia y que presentaría su renuncia. }\end{array}$ \\
& & \\
\hline
\end{tabular}

